\title{
Long-Term rAAV-Mediated Gene Transfer of GDNF in the Rat Parkinson's Model: Intrastriatal But Not Intranigral Transduction Promotes Functional Regeneration in the Lesioned Nigrostriatal System
}

\author{
Deniz Kirik, Carl Rosenblad, Anders Björklund, and Ronald J. Mandel \\ Wallenberg Neuroscience Center, Department of Physiological Sciences, Division of Neurobiology, Lund University, \\ 22362 Lund, Sweden
}

Previous studies have used recombinant adeno-associated viral ( $\mathrm{rAAV}$ ) vectors to deliver glial cell line-derived neurotrophic factor (GDNF) in the substantia nigra to protect the nigral dopamine (DA) neurons from 6-hydroxydopamine-induced damage. However, no regeneration or functional recovery was observed in these experiments. Here, we have used an rAAVGDNF vector to express GDNF long-term (6 months) in either the nigral DA neurons themselves, in the striatal target cells, or in both of these structures. The results demonstrate that both nigral and striatal transduction provide significant protection of nigral DA neurons against the toxin-induced degeneration. However, only the rats receiving rAAV-GDNF in the striatum displayed behavioral recovery, accompanied by significant reinnervation of the lesioned striatum, which developed gradually over the first 4-5 months after the lesion. GDNF transgene expression was maintained at high levels throughout this period. These results provide evidence that rAAV is a highly efficient vector system for long-term expression of therapeutic proteins in the nigrostriatal system.

Key words: Parkinson's disease; 6-hydroxydopamine; glial cell line-derived neurotrophic factor; gene transfer; tyrosine hydroxylase; stepping; paw use; sensorimotor behavior; cell death; stereology
Glial cell line-derived neurotrophic factor (GDNF) has been demonstrated to be a potent factor for protection of nigral dopamine (DA) neurons against toxin-induced degeneration in vivo (Björklund et al., 1997; Gash et al., 1998; Bohn, 1999). Injections of GDNF close to substantia nigra can substantially protect nigral DA neurons from the acute toxin-induced degeneration, provided that it is administered before onset of cell loss (Beck et al., 1995; Sauer et al., 1995; Winkler et al., 1996; Lu and Hagg, 1997; Sullivan et al., 1998; Rosenblad et al., 2000b). However, survival of the DA cell bodies alone, in the absence of a functional striatal DA innervation, is not sufficient for preservation of intact motor performance (Winkler et al., 1996; Rosenblad et al., 2000b; D. Kirik, C. Rosenblad, and A. Björklund, unpublished observations). Thus, in the intrastriatal 6-hydroxydopamine (6-OHDA) lesion model, longterm delivery of GDNF to the striatum may be necessary to obtain efficient axonal regeneration and functional recovery.

In vivo gene transfer has been explored as a relatively noninvasive method to deliver long-term GDNF to the brain using adenoviral, lentiviral, or adeno-associated viral (AAV) vectors (Bilang-Bleuel et al., 1997; Choi-Lundberg et al., 1997, 1998;

Received Jan. 18, 2000; revised March 17, 2000; accepted March 27, 2000.

The work was supported by grants from the Swedish Medical Research Council (National Gene Therapy Program 99XG-13285) and the Parkinson's Disease Foundation. We thank Cell Genesys Inc. for the generous gift of the rAAV vectors used in these experiments, and Alicja Flasch, Kerstin Fogelström, and Ulla Jarl for excellent technical support. Richard O. Snyder and Brian A. Donahue produced the vectors described herein.

Correspondence should be addressed to Deniz Kirik, Wallenberg Neuroscience Center, Department of Physiological Sciences, Lund University, Sölvegatan 17, 22362 Lund, Sweden. E-mail: deniz.kirik@mphy.lu.se.

Dr. Mandel's current address: Gene Therapy Center, Department of Neuroscience, University of Florida College of Medicine, P.O. Box 100244, Gainesville, FL 32610-0244.

Copyright (C) 2000 Society for Neuroscience $\quad 0270-6474 / 00 / 204686-15 \$ 15.00 / 0$
Mandel et al., 1997; Connor et al., 1999; Mandel et al., 1999; Deglon et al., 2000; Rosenblad et al., 2000a). Recombinant AAV (rAAV)-based vectors are particularly interesting for gene transfer to the nervous system in that they are able to transduce postmitotic neurons and support long-term transgene expression in the brain (Kaplitt et al., 1994; Peel et al., 1997; Bartlett et al., 1998; Klein et al., 1998; Mandel et al., 1998; Leff et al., 1999; Lo et al., 1999; Szczypka et al., 1999). There have been no reports of neurotoxicity or immune reactions in response to rAAV injections, presumably because of the lack of expression of any viral proteins after transduction with this vector (Muzyczka, 1992; Kaplitt et al., 1994). In the nigrostriatal system, rAAV vectors have been shown to be effective in transducing neurons in both striatum and substantia nigra, and high levels of transgene expression have been maintained for at least 3-6 months (Kaplitt et al., 1994; Klein et al., 1998; Leff et al., 1999; Lo et al., 1999; Szczypka et al., 1999). The particular affinity of the rAAV vectors for the nigral DA neurons and their targets raises the possibility that rAAV-mediated gene transfer can be used to compare the effects of long-term GDNF expression within the nigral DA neurons with the effects induced by long-term GDNF delivery in the striatum acting on the lesioned nigrostriatal afferents.

We report here that protection of nigral DA neurons against 6-OHDA-induced damage can be achieved by rAAV-GDNF transduction of either substantia nigra or striatum, but that longterm functional recovery and regeneration of the lesioned nigrostriatal projection in the intrastriatal 6-OHDA lesion model is obtained only when GDNF is expressed over an extended time period in the striatum alone. This suggests that paracrine rather than autocrine mechanisms are important for functional regeneration in the lesioned nigrostriatal DA system. 
Table 1. Stereotaxic coordinates for the rAAV and 6-OHDA injections

rAAV injection

\begin{tabular}{|c|c|c|c|c|c|c|c|c|c|}
\hline \multirow{3}{*}{$\begin{array}{l}\text { Injection } \\
\text { sites }\end{array}$} & \multicolumn{5}{|c|}{ rAAV injection } & \multirow{2}{*}{\multicolumn{4}{|c|}{$\begin{array}{l}\text { 6-OHDA injection } \\
7 \mu \mathrm{g} \text { free base in } 2 \mu \text { per site }\end{array}$}} \\
\hline & \multicolumn{3}{|c|}{ Striatum } & \multicolumn{2}{|c|}{ Nigra } & & & & \\
\hline & 1 & 2 & 3 & 1 & 2 & 1 & 2 & 3 & 4 \\
\hline AP & +1.2 & +0.2 & -0.8 & -4.8 & -5.8 & +1.3 & +0.4 & -0.4 & -1.3 \\
\hline ML & -3.0 & -3.4 & -4.4 & -2.0 & -2.0 & -2.6 & -3.0 & -4.2 & -4.5 \\
\hline DV & $-5.5^{a}$ & $-5.5^{a}$ & $-5.5^{a}$ & -7.2 & -7.2 & -5.0 & -5.0 & -5.0 & -5.0 \\
\hline Tooth bar & 0.0 & 0.0 & 0.0 & -2.3 & -2.3 & 0.0 & 0.0 & 0.0 & 0.0 \\
\hline
\end{tabular}

AP and ML are mm from bregma; DV is $\mathrm{mm}$ from dura.

${ }^{a}$ Intrastriatal injections start at DV -5.5 from the dura, and the micropipette is pulled up to -4.5 and -3.5 during injection.

\section{MATERIALS AND METHODS}

Recombinant $A A V$ vector production. The rAAV-CMV-GFP and rAAVMD-GDNF vectors were prepared as described previously (McCown et al., 1996; Mandel et al., 1997). Briefly, rAAV vectors were prepared according to Snyder et al. (1996) with modifications as in Mandel et al. (1997). Subconfluent 293 cells were cotransfected with the vector plasmid and the AAV helper plasmid using the calcium phosphate method. Cells were then infected with Adenovirus Ad5 dl312 at an MOI of 2, and the infection was allowed to proceed for 60-72 hr. Cells were harvested and three freeze/thaw cycles were performed to lyse the cells. The cell lysate was fractionated by ammonium sulfate precipitation, and the rAAV virions were isolated on two sequential continuous $\mathrm{CsCl}$ gradients. The final particle titer of the rAAV-CMV-GFP was $1.4 \times 10^{12}$ viral particles per milliliter, and the rAAV-MD-GDNF was $1.0 \times 10^{12}$ viral particles per milliliter as estimated by dot blot analysis.

Subjects. A total of 58 young female Sprague Dawley rats (B\&K Universal, Stockholm, Sweden) were housed four to five in a cage with free access to rat chow and water during a $12 \mathrm{hr}$ light/dark cycle. The housing and treatment of the animals were performed according to rules set by the Ethical Committee for Use of Laboratory Animals at Lund University.

Surgical procedures. For all of the surgical procedures described herein, animals received equithesin anesthesia ( $3 \mathrm{ml} / \mathrm{kg}$, i.p.) before surgery. After anesthesia, the animals were placed into stereotaxic frames (Kopf Instruments, Tujunga, CA). All injections were made using a continuous infusion system (Carnegie Medicin, Stockholm, Sweden) that was attached to a $10 \mu \mathrm{l}$ Hamilton microsyringe fitted with a glass micropipette (outer diameter $60-80 \mu \mathrm{m}$ ). The anterior-posterior (AP) and mediallateral (ML) stereotaxic coordinates were calculated from bregma, and the dorso-ventral (DV) coordinates were calculated from the dural surface. A burr hole was drilled in the skull at the calculated coordinates. At the position of the entry of the glass pipette, a small cut in the dura was made using a 28 gauge stainless steel hypodermic needle.

Injection of $A A V$ vectors. The animals received injections of rAAV (either rAAV-MD-rGDNF or rAAV-CMV-GFP) suspended in PBS into the striatum ( $3 \mu \mathrm{l}$ per site, $9 \mu \mathrm{l}$ in total), substantia nigra $(2 \mu \mathrm{l}$ per site, $4 \mu \mathrm{l}$ in total), or both. Coordinates are shown in Table 1 . The injection rate was $1 \mu \mathrm{l} / \mathrm{min}$ in the striatum and $0.5 \mu \mathrm{l} / \mathrm{min}$ in the nigra. During intrastriatal injections the glass pipette was slowly retracted $1 \mathrm{~mm}$ every minute. One minute after the cessation of the infusion, the micropipette was retracted $1 \mathrm{~mm}$ further and left in place for an additional 2 min before it was slowly retracted from the brain. Experimental groups used in this experiment will be referred to in the text as follows: (1) rAAV-GDNF injected into SN $(n=10)$ is referred to as "SN group"; (2) rAAV-GDNF injected into STR $(n=11)$ is referred to as "STR group"; (3) rAAV-GDNF injected into SN and STR $(n=11)$ is referred to as "SN+STR group"; (4) two control groups consisting of rAAV-GFP into substantia nigra and striatum (GFP control group, $n=6$ ) or non-vectorinjected lesion-only group $(n=5)$. These two control groups were indistinguishable with regard to all variables tested and were therefore combined into one "control group" $(n=11)$ for all analyses and figures; (5) rAAV-GDNF injected into SN $(n=5)$, STR $(n=5)$, or SN+STR $(n=5)$. These animals were killed at 4 weeks after the virus injection to determine the tissue levels of GDNF protein and dopamine and its metabolites; (6) rAAV-GFP injected into SN $(n=4)$. These animals were killed at 4 weeks after the injection and were processed for GFP immunohistochemistry.

6-OHDA lesions. Four weeks after virus injections, all animals, except those in groups 5 and 6, received unilateral stereotaxic injections of a total of $28 \mu \mathrm{g}$ of 6-OHDA (calculated as free base; Sigma, St. Louis, MO) dissolved in ascorbate-saline $(0.05 \%)$ divided into four $7 \mu \mathrm{g}$ deposits in the right striatum. The injection rate was $1 \mu \mathrm{l} / \mathrm{min}$, and the micropipette was left in place for an additional 2 min before it was slowly retracted. The coordinates used (see Table 1 ) were based on the findings of our previous experiment (Kirik et al., 1998).

\section{Behavioral analysis}

Rotational behavior. All rotational testing was performed in automated rotometer bowls (Ungerstedt and Arbuthnott, 1970). Spontaneous rotation was monitored over $30 \mathrm{~min}$ to determine whether the animals displayed asymmetric behavior. The data are presented as total number of full $360^{\circ}$ rotations in ipsilateral and contralateral directions. The activity of the animals was assessed by calculating the total number of rotations regardless of the direction. Drug-induced rotational asymmetry was assessed using apomorphine- $\mathrm{HCl}$ (Research Biochemicals Incorporated; $0.25 \mathrm{mg} / \mathrm{kg}$, s.c.), SKF-82958 HCl (full D1 dopamine agonist, Research Biochemicals Incorporated; $0.1 \mathrm{mg} / \mathrm{kg}$, s.c.), and D-amphetamine sulfate (Apoteksbolaget; 1.0 or $2.5 \mathrm{mg} / \mathrm{kg}$, i.p.). Rotations were monitored for 40,60 , and $90 \mathrm{~min}$ for apomorphine, SKF-82958, and D-amphetamine, respectively. All druginduced rotational asymmetry scores are expressed as full $360^{\circ}$ rotations per minute, with ipsilateral rotations assigned a positive value.

Forelimb akinesia (stepping test). The animals were tested for forelimb akinesia in a stepping test (Schallert et al., 1992) as described by Olsson et al. (1995). The test was performed twice daily on four consecutive days with the mean of the data taken from the last $3 \mathrm{~d}$ constituting the final dependent variable.

Cylinder test. This test, which is a modification of a motor test of forelimb asymmetry described first by Schallert and Lindner (1990), was performed as described by Schallert and Tillerson (1999). Briefly, during video recording, the animal is allowed to move freely in a clear glass cylinder until it has performed 10 rears during which it places at least one paw on the cylinder wall. Mirrors are placed behind the cylinder so that the video camera can have visual access to all paw placements around the cylinder. An observer blinded to animal identities viewed the videotapes and counted the number of left and right forepaw contacts to the walls of the cylinder from a minimum of 20 contacts. The data are presented contralateral (left) forepaw contacts as percentage of total.

Staircase (paw reaching) test. A modified version of the staircase test described by Montoya et al. (1991) was used. The animals received food pellets in their home cages just before a 2 d food deprivation period, leading to $\sim 15 \%$ loss in body weight. The animals were then placed into Plexiglas test boxes and were tested for $15 \mathrm{~min}$ on 7 consecutive days. At this point, the standard central platform $(27 \mathrm{~mm})$ was replaced with a wider platform $(34 \mathrm{~mm})$ to make the task more difficult, and the animals were tested for an additional $5 \mathrm{~d}$. After each test the number of pellets taken from the stairs and the number of misses were counted separately. The difference between the pellets taken and misses constitutes the total number of successful retrievals, which serves as the dependent variable for statistics and graphical representation.

Prelesion behavioral testing. To be able to monitor the effects of GDNF overexpression in the intact rats (Horger et al., 1998), the animals were tested before 6-OHDA lesion on the stepping test and the spontaneous and amphetamine-induced rotational asymmetry tests. The stepping test was performed during the 3 rd week after the injection of the virus. After the stepping test was completed, spontaneous rotation was monitored over a $30 \mathrm{~min}$ period, which was followed by the amphetamine-induced 
rotation test. The animals in each group were divided into two subgroups and received either 1.0 or $2.5 \mathrm{mg} / \mathrm{kg}$ D-amphetamine sulfate intraperitoneally over 2 weeks with the subgroups receiving alternate doses in a crossover design (Cochran and Cox, 1957).

Post-lesion behavioral testing. Amphetamine-induced rotational behavior was monitored at $4,7,10,13,16$, and 22 weeks after the lesion. Stepping tests were performed during the 3rd, 7th, 14th, 18th, and 22nd week after the lesion. Before the first and after the last post-lesion stepping tests, the animals were videotaped in the cylinder test. Starting at the 20th week after lesion, the animals were tested in the staircase test as described above (for details, see Fig. 1). Apomorphine-induced rotation was monitored at 3 and 18 weeks after lesion. Four days after each apomorphine administration, animals received subcutaneous injections of SKF-82958. The two control groups (the GFP control group and the lesion-only group) did not differ from each other in any of the tests, and therefore their data were pooled for further analysis.

\section{Biochemical analysis}

Tissue levels of GDNF and dopamine and its metabolites. To determine the level of GDNF protein, DA, and DA metabolites from the same samples, at the time of 6-OHDA lesion, 15 rats received rAAV-MD-GDNF into SN $(n=5)$, STR $(n=5)$, and SN/STR $(n=5)$ as described above. Four weeks after vector injection, the virus-injected animals and five naive control animals were injected with the l-aromatic amino acid decarboxylase inhibitor NSD-1015 (Sigma, $100 \mathrm{mg} / \mathrm{kg}$, i.p.) $30 \mathrm{~min}$ before they were killed. DOPA decarboxylase inhibition results in accumulation of DOPA that would otherwise be converted to DA, thus providing an opportunity to determine in vivo measure of striatal tyrosine hydroxylase (TH) activity. The animals were then deeply anesthetized with sodium pentobarbital and decapitated. The brains were rapidly removed, and the corpora striata were dissected dorsal to the anterior commissure and freed from cortex and septal nuclei. The dissected tissue was then chopped into small pieces, mixed, and divided equally into two halves and frozen separately (one part for GDNF ELISA, and the other for DOPA, DA, and DOPAC measurements). A 2- to 3-mm-diameter punch centered on the substantia nigra pars compacta on each side was taken from a $3 \mathrm{~mm}$ thick coronal slice that contained the rAAV vector injection site.

For determination of tissue GDNF protein levels, tissue from the striatum and nigra were sonicated (Vibra Cell Sonics and Materials Inc., Danbury, CT) in a homogenization buffer $(150 \mathrm{~mm} \mathrm{NaCl}, 50 \mathrm{~mm}$ HEPES, pH 7.4, 1\% Triton X-100, 1 mm phenylmethylsulfonyl fluoride, and $0.6 \mu \mathrm{M}$ leupeptin) at a tissue concentration of $50 \mathrm{mg} / \mathrm{ml}$ (wet weight per volume). Tissue levels of GDNF were determined from tissue homogenates by ELISA using a commercial kit, according to supplier's recommendations (G3240; Promega, Madison, WI). The standard curves for determining GDNF levels in tissue samples were undertaken using rat GDNF protein (a generous gift of Dr. H. Phillips, Genentech, Inc.).

For determination of DOPA, DA, and DOPAC levels, the striatal pieces were immediately frozen in liquid nitrogen and stored until assayed by a combined radioenzymatic method, as described by Schmidt et al. (1982).

\section{Histology}

Perfusion and tissue processing. After the behavioral testing was completed (24 weeks post-lesion), the animals were deeply anesthetized with pentobarbital and perfused through the ascending aorta with $50 \mathrm{ml}$ of isotonic saline, followed by $250 \mathrm{ml}$ of ice-cold $4 \%$ paraformaldehyde in $0.1 \mathrm{M}$ phosphate buffer (PB), $\mathrm{pH}$ 7.4. Brains were removed and post-fixed for $2 \mathrm{hr}$ in the same solution and then transferred to $20 \%$ sucrose in 0.1 M PB before sectioning on a freezing-stage microtome at $40 \mu \mathrm{m}$.

Immunohistochemistry. Standard immunohistochemical procedures were used as described previously (Sternberger et al., 1970). For TH immunohistochemistry, the sections were preincubated with 5\% normal horse serum (NHS) and then incubated overnight at room temperature with a 1:2000 dilution of mouse anti-TH antibody (Chemicon, Temecula, CA) in $2 \%$ NHS. For GDNF immunohistochemistry, the sections were preincubated with $5 \%$ NHS and then incubated overnight at room temperature with a 1:1000 dilution of goat anti-GDNF antibody (R\&D systems) in 2\% NHS. GFR $\alpha-1$ immunohistochemistry was performed by preincubation with 5\% normal swine serum (NSS) and followed by incubation overnight at $4^{\circ} \mathrm{C}$ with a 1:500 dilution of rabbit anti-GFR $\alpha-1$ antibody (a kind gift from Dr. C. Ibanez, Karolinska Institute, Stockholm) in 2\% NSS. Appropriate secondary antibodies directed against the species in which the primary antibody was raised were used in all cases. In all staining protocols, incubation with the secondary antibody was followed by incubation with avidin-biotin-peroxidase complex (ABC, Vector Laboratories, Burlingame, CA). The reactions were visualized using 3,3-diaminobenzidine as a chromogen. Sections were mounted on chrome-alum-coated slides, dehydrated in ascending alcohol concentrations, cleared in xylene, and coverslipped in Depex.

\section{Morphometric analysis}

Nigral cell counts. The unbiased stereological estimation of the total number of the cells in substantia nigra was made using the optical fractionator, as described in detail previously (Kirik et al., 1998). This sampling technique is not affected by tissue volume changes and does not require reference volume determinations (West et al., 1991). The sections used for counting covered the entire substantia nigra, from the rostral tip of the pars compacta back to the caudal end of the pars reticulata. This yielded 9-11 sections in a series. Sampling was performed using the Olympus C.A.S.T.-Grid system (Olympus Denmark A/S, Albertslund, Denmark). A counting frame $\left(5445 \mu \mathrm{m}^{2}\right)$ was placed randomly on the first counting area and systematically moved through all counting areas until the entire delineated area was sampled. Actual counting was performed using a $100 \times$ oil objective (NA 1.4). Guard volumes ( $5 \mu \mathrm{m}$ from the top and 5-8 $\mu \mathrm{m}$ from the bottom of the section) were excluded from both surfaces to avoid the problem of lost caps, and only the profiles that came into focus within the counting volume (with a depth of $10 \mu \mathrm{m}$ ) were counted. The total number of neurons was calculated according to the optical fractionator formula [for more details, see West et al. (1991)]. The coefficient of error (CE) attributable to the estimation was calculated according to Gundersen and Jensen (1987). CE $<0.10$ was accepted.

Striatal fiber density measurements. The optical densities of the THimmunoreactive fibers in the striatum were measured using the NIH 1.62 Image program on a Macintosh 9500 computer connected to a digital camera (ProgRes) and a constant illumination table. For each animal the optical density was measured at seven rostocaudal levels over the whole striatum according to the atlas of Paxinos and Watson (1998): (1) AP, +1.6; (2) AP, +1.0; (3) AP, +0.2; (4) AP, -0.3 ; (5) AP, -0.9 ; (6) AP, -1.4 ; and (7) AP, -2.1 relative to bregma. To estimate the specific TH staining density, the optical density readings were corrected for nonspecific background density, as measured from a completely denervated part of the striatum.

\section{Statistical analysis}

Significant differences between different treatments were assessed using parametric analysis of variance (ANOVA). Individual contrasts among means were used only when there was a significant interaction term within the ANOVA, in the form of simple-main effects analysis using Systat 5.2.1 (Kirk, 1968). Post hoc testing between the groups consisted of Tukey honestly significant difference (HSD). The Greenhouse-Geisser Epsilon test, to determine homogeneity of variance among groups subjected to ANOVAs, yielded nonsignificant results for all contrasts $(p>$ 0.05 ). The staircase data were subjected to a logarithmic transformation to control the variability attributable to the poor performance of some animals early in the acquisition phase of the learning. Significance was accepted at the $95 \%$ probability level.

\section{RESULTS}

The study was designed to determine whether long-term overexpression of GDNF in striatum and/or substantia nigra by rAAVmediated gene transfer may provide protection of the nigrostriatal pathway and promote regeneration and functional recovery in the intrastriatal 6-OHDA lesion model. The rAAV-GDNF vector was injected unilaterally into striatum (STR group, $n=11$ ) or substantia nigra (SN group, $n=10)$ or both structures $(\mathrm{SN}+\mathrm{STR}$ group, $n=11$ ). Rats injected with an rAAV encoding green fluorescent protein (GFP, $n=6$ ) and a group of uninjected rats $(n=5)$ served as control. Vector injections were made 4 weeks before the intrastriatal 6-OHDA injection to allow sufficient time for the GDNF gene to be fully expressed (Mandel et al., 1997, 1999). To induce consistent long-lasting deficits in motor behavior and substantial DA cell loss, a four-site intrastriatal 6-OHDA lesion was applied (Kirik et al., 1998). The 6-OHDA-lesioned animals were allowed to survive for 6 months during which time 


\section{Time course of the experiment}

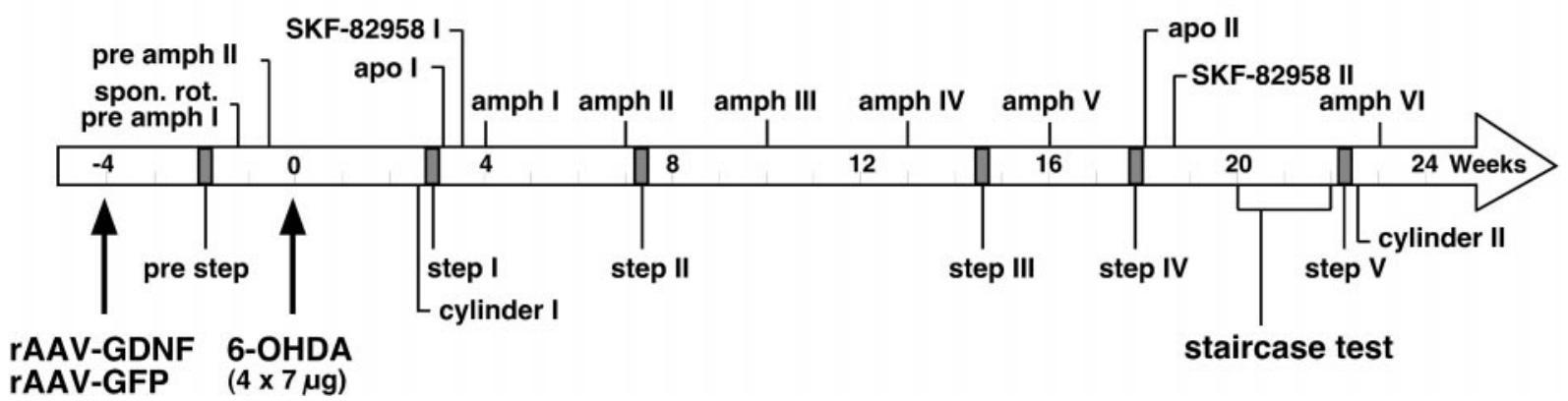

Figure 1. Schedule of surgeries and testing. The animals received injections of the viral vectors 4 weeks before the 6-OHDA lesion ( -4$)$. Beginning 3 weeks after the vector injection, the animals were tested for forelimb akinesia using the stepping test (pre step), followed by spontaneous motor asymmetry (spon. rot.) and D-amphetamine-induced motor asymmetry ( pre amph I-II). 6-OHDA was injected into four sites in the striatum at a dose of $7 \mu \mathrm{g}$ per site at week 0. Post-lesion motor impairment was evaluated using repeated drug-induced (amph I-VI, apo I-II, and SKF-82958 I-II; shown above the time line) and spontaneous tests (step I-V, cylinder and staircase tests; below the time line). The animals were perfused for immunohistochemical analysis at 24 weeks after lesion, as described in Materials and Methods.

Table 2. GDNF protein levels (ng/mg tissue) measured by ELISA in punches from striatum and the substantia nigra region at 4 weeks after rAAV-GDNF injection

\begin{tabular}{llllll} 
& Striatum & & & Nigra & \\
\cline { 2 - 3 } \cline { 5 - 6 } & $\begin{array}{l}\text { Left side } \\
\text { (non-injected) }\end{array}$ & $\begin{array}{l}\text { Right side } \\
\text { (injected) }\end{array}$ & & $\begin{array}{l}\text { Left side } \\
\text { (non-injected) }\end{array}$ & $\begin{array}{l}\text { Right side } \\
\text { (injected) }\end{array}$ \\
\hline SN group $(n=5)$ & $0.07 \pm 0.02$ & $1.58 \pm 0.31^{a}$ & & $0.09 \pm 0.02$ & $1.41 \pm 0.49^{a}$ \\
STR group $(n=5)$ & $0.02 \pm 0.01$ & $0.22 \pm 0.09^{a}$ & & $0.05 \pm 0.03$ & \\
SN + STR group $(n=4)$ & $0.05 \pm 0.04$ & $2.28 \pm 0.35^{a}$ & & $0.10 \pm 0.04$ & $1.00 \pm 0.11^{a}$ \\
\hline
\end{tabular}

Means \pm SEM.

${ }^{a}$ Different from noninjected side $p<0.05$ (ANOVA followed by post hoc Tukey HSD).

they were repeatedly tested on a battery of drug-induced and spontaneous motor behaviors (Fig. 1).

\section{GDNF expression in intact animals}

GDNF expression at the time of the lesion was assessed by ELISA in tissue samples obtained from a separate group of nonlesioned animals $(n=14)$ that were killed 4 weeks after vector injection (Table 2). Detectable levels of GDNF protein were measured in the transduced nigra and striatum in all three rAAV-GDNF-injected groups (0.22-2.28 ng/mg tissue, $4-$ to 35 fold above baseline; effect of side $\left.F_{(1,22)}=16.1, p<0.0001\right)$. GDNF levels were $\sim 10$-fold higher in the animals that had received vector injections in the nigra alone (the $\mathrm{SN}$ group), or in both nigra and striatum (the $\mathrm{SN}+\mathrm{STR}$ group), than in the striatum-injected animals (the STR group) (effect of group $F_{(2,22)}$ $=73.4, p<0.0001)$. The high level of GDNF in the striatum in the SN group, moreover, suggests that the GDNF protein had been transported from the nigra to the striatum in the animals that had received vector injections in the $\mathrm{SN}$.

In vivo $\mathrm{TH}$ enzyme activity (measured as the rate of L-DOPA accumulation after inhibition of the decarboxylase enzyme) and DA turnover (estimated as the DOPAC/DA ratio) were measured bilaterally in the striatum in the same group of animals. As shown in Table 3, there was a two- to threefold increase in DA turnover on the vector-injected side in all rAAV-GDNF-injected groups, whereas a significant increase in TH activity was detected only in the combined SN+STR group.

The impact of GDNF overexpression on the behavior of the intact animals was assessed during the third week after vector injection, i.e., during the week preceding the 6-OHDA lesion. The
Table 3. DOPA levels and DOPAC/DA ratios in the striatum in non-lesioned control and rAAV-GDNF-injected animals, 4 weeks after injection

\begin{tabular}{lcl} 
Experimental group & DOPA $(\mathrm{fmol} / \mathrm{mg}$ tissue $)$ & DOPAC/DA \\
\hline Control $(n=5)$ & $759.2 \pm 44.8$ & $0.021 \pm 0.003$ \\
SN group $(n=5)$ & $538.4 \pm 211.9$ & $0.048 \pm 0.008^{a}$ \\
STR group $(n=4)$ & $975.3 \pm 89.8$ & $0.046 \pm 0.004^{a}$ \\
SN + STR group $(n=4)$ & $1905.3 \pm 345.9^{b}$ & $0.065 \pm 0.014^{a}$ \\
\hline
\end{tabular}

All animals were pretreated with NSD-1015 (100 mg/kg) $30 \mathrm{~min}$ before they were killed.

${ }^{a} p<0.05$, different from control.

${ }^{b} p<0.05$, different from all other groups.

rAAV-GDNF-injected animals in the $\mathrm{SN}$ and $\mathrm{SN}+\mathrm{STR}$ groups showed a significant spontaneous contralateral turning bias (i.e., in the direction away from the vector-injected hemisphere) (Fig. 2A), as well as an increased general locomotor activity (total rotations in both directions) compared with the controls $\left(F_{(3,39)}=6.18, p=\right.$ $0.001)$. Although a twofold increase in contralateral rotations was observed in the STR group versus the control group, this asymmetry did not reach statistical significance. These differences were further accentuated after challenge with D-amphetamine (Fig. 2B); i.e., all three rAAV-GDNF-injected groups showed strong amphetamine-induced contralateral rotation, and they were significantly more active in the test, as indicated by an increase in the total number of turns during the 90 min test $\left(F_{(3,39)}=9.284, p<\right.$ $0.0001)$. On the other hand, the rAAV-GDNF-treated animals displayed normal forelimb stepping behavior before the 6-OHDA lesion $\left(F_{(3,78)}=0.15, p=0.93\right)$ (Fig. $4 E, F$, pre-lesion values). 
A. Pre-lesion spon rotation

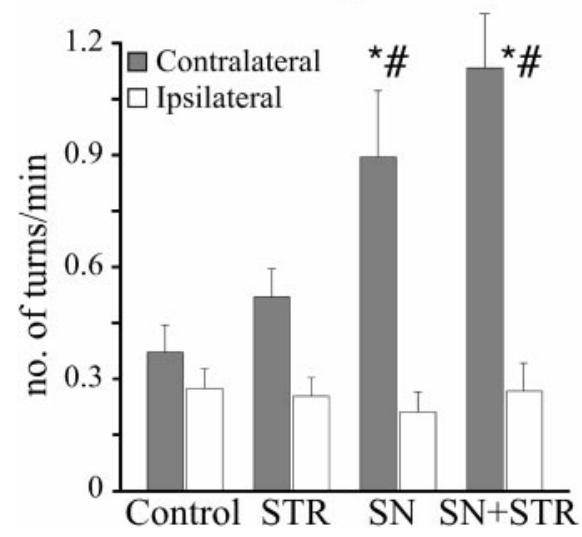

B. Pre-lesion amph rotation

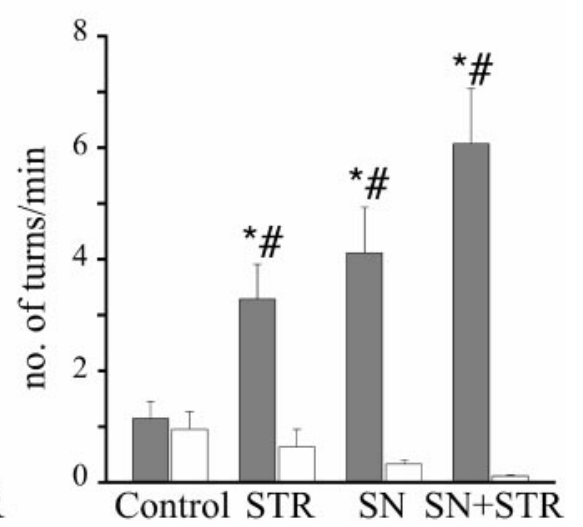

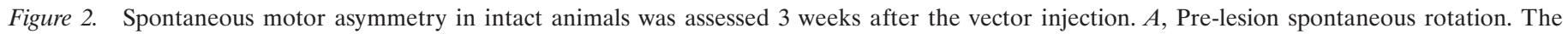

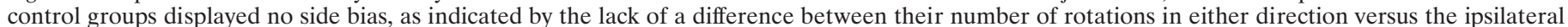

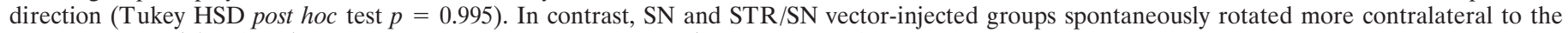

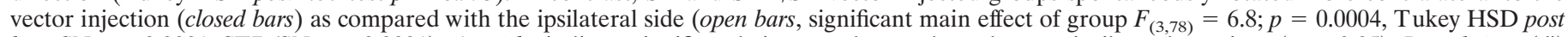

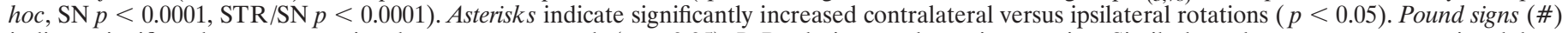

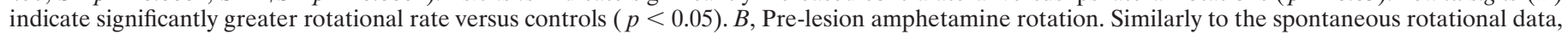

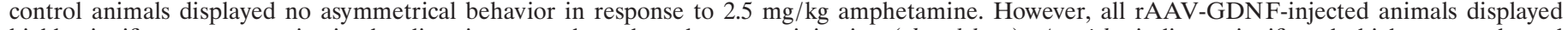

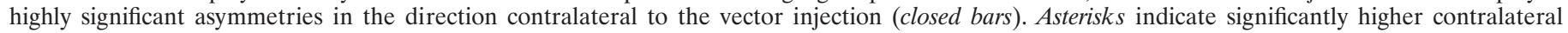

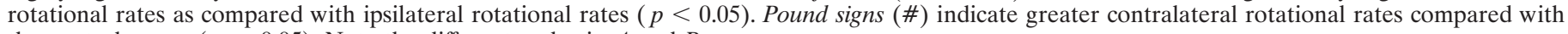
the control group $(p<0.05)$. Note the different scales in $A$ and $B$.

Taken together, these data indicate that the level of overexpression of GDNF obtained in the rAAV-GDNF-injected animals was sufficient to induce a marked functional upregulation in the intact nigrostriatal DA neurons and that this effect was most pronounced in the SN+STR group. Moreover, the contralateral turning bias (spontaneously and after amphetamine challenge) was strongest in those groups that displayed the highest level of striatal GDNF and weakest in those groups with lower GDNF levels (Table 2).

\section{Reversal of lesion-induced functional impairments by rAAV-mediated GDNF delivery}

Beginning 3 weeks after the intrastriatal 6-OHDA lesion, the animals were tested on a battery of drug-induced and spontaneous motor tests (Fig. 1). In the tests performed 3-5 weeks after the lesion, all vector-injected groups showed a similar degree of impairment both in the drug-induced rotation tests (Fig. 3, Table 4) and in the spontaneous motor tests (forelimb akinesia and paw-use tests) (Fig. 4). These data indicate that the acute impact of this large 6-OHDA lesion was the same in all four experimental groups.

Over the subsequent weeks, significant functional recovery was observed in the STR group, both in amphetamine-induced rotation (Fig. 3) and in the animals' ability to use their forelimbs (cylinder and staircase tests) (Fig. 4A-D). In contrast, neither the $\mathrm{SN}$ nor the $\mathrm{SN}+\mathrm{STR}$ groups showed any significant recovery in any of the behavioral tests. The improvement in the STR group, as demonstrated by reduced amphetamine-induced rotational behavior, developed gradually over time until 23 weeks after the 6-OHDA lesion. At 23 weeks, the asymmetry was completely abolished in 8 of the 11 rats in the STR group. These fully recovered animals had also recovered normal forelimb use in the cylinder test (Fig. 4B). In contrast, rotation in response to the mixed D1/D2 agonist apomorphine or the D1 agonist SKF-82958 was unaffected at all time points (Table 4).

To further characterize the ability of the rAAV-GDNF-treated

\section{D-amphetamine rotation}

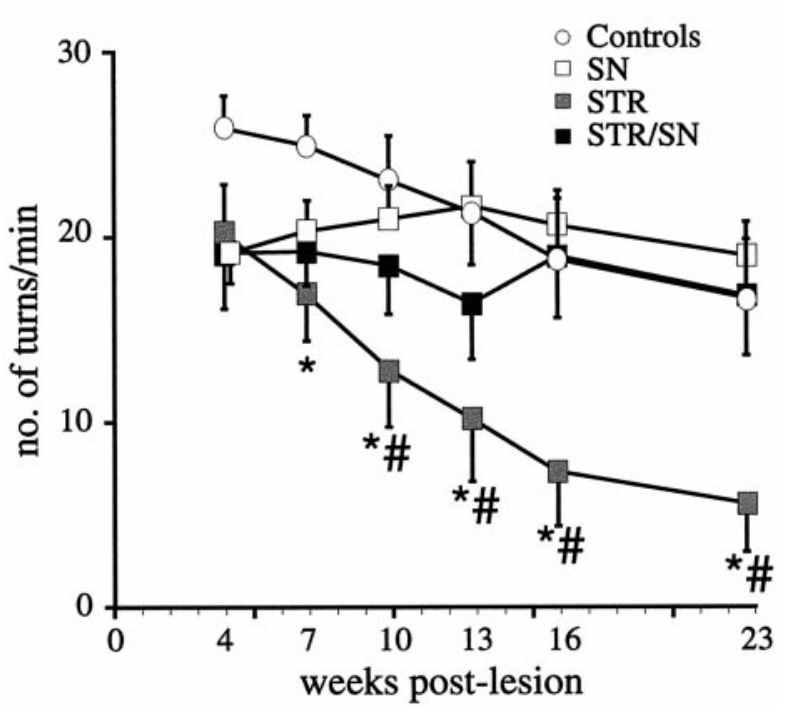

Figure 3. Post-lesion amphetamine-induced motor asymmetry. Four weeks after the striatal 6-OHDA lesion, all groups showed clear ipsilateral rotation that was equivalent among the groups $(p>0.5$, simple main effects). However, as early as 7 weeks after the 6-OHDA lesion, the STR vector-injected group began to display reduced amphetamine-induced rotations. From 10 weeks and onward, the STR group was significantly different from all other groups (main effect of group; $F_{(3,39)}=3.464, p=$ $0.03)$. Asterisks indicate a significant difference from earlier time points within the STR group, and the pound sign (\#) denotes a significant difference from all other groups ( $p<0.05$ by simple main effects). All values are means \pm SEM.

rats to use their affected forelimb, two different versions of a staircase test were performed. The first $7 \mathrm{~d}$ of testing was performed using a platform of a standard width (Fig. 4C, narrow platform). During this initial period of the test, the STR group was able to successfully retrieve more pellets with their contralat- 
Table 4. Apomorphine $(0.25 \mathrm{mg} / \mathrm{kg})$ and SKF-82958 $(0.1 \mathrm{mg} / \mathrm{kg})$ induced rotation (full turns/min)

\begin{tabular}{|c|c|c|c|c|}
\hline & \multicolumn{2}{|c|}{ Apomorphine } & \multicolumn{2}{|l|}{ SKF-82958 } \\
\hline & 5 weeks & 18 weeks & 5 weeks & 18 weeks \\
\hline Control $(n=5)$ & $-6.2 \pm 1.4$ & $-6.2 \pm 0.9$ & $-10.9 \pm 2.0$ & $-7.1 \pm 2.1$ \\
\hline $\mathrm{SN}$ group $(n=5)$ & $-8.9 \pm 0.9$ & $-9.8 \pm 0.9$ & $-13.0 \pm 2.0$ & $-11.6 \pm 1.7$ \\
\hline STR group $(n=4)$ & $-9.7 \pm 1.3$ & $-8.3 \pm 0.9$ & $-12.2 \pm 2.5$ & $-6.1 \pm 1.7$ \\
\hline $\mathrm{SN}+\mathrm{STR}$ group $(n=4)$ & $-9.1 \pm 1.2$ & $-10.3 \pm 1.0$ & $-13.7 \pm 1.9$ & $-12.6 \pm 2.0$ \\
\hline
\end{tabular}

Mean \pm SEM at 5 and 18 weeks after the 6-OHDA lesion.

eral paw than all other groups over the entire test period (Fig. $4 C$ ). After asymptotic performance was reached, the standard platform was replaced by a wider platform to make the test more difficult for an additional $5 \mathrm{~d}$. During the second $5 \mathrm{~d}$ testing period (Fig. 4C, days 8-12), the STR group again performed better than all other groups. In addition, in the second more difficult test the SN group tended to perform worse than the other groups and performed significantly worse than the STR group on all days (simple main effects, $p<0.025$ on all days) and the remaining groups on two of the days (Fig. $4 C$ ). In contrast to the improvements observed in staircase and cylinder tests, contralateral (left) forelimb use in the stepping test was severely impaired in all groups and remained impaired throughout the experiment in all groups (Fig. 4E,F).

\section{Preservation of the integrity of the nigrostriatal pathway in rAAV-GDNF-treated animals}

The protection of the nigral DA neurons and the preservation of the nigrostriatal projection was evaluated by $\mathrm{TH}$ immunohistochemistry. Four coronal levels were chosen for illustration of the status of the nigrostriatal pathway: the central striatum (Fig. 5), caudal striatum and globus pallidus (GP) (Fig. 6), medial forebrain bundle (MFB) (Fig. 7), and substantia nigra (Fig. 8).

In the control group, the four-site intrastriatal 6-OHDA injection induced an extensive loss of TH-positive neurons $(>85 \%)$ in the substantia nigra pars compacta (Fig. $8 B$, and inset) as compared with the intact hemisphere (Fig. $8 A$ ). There was a similar loss of TH innervation in large portions of the striatum, with the exception of some spared fibers that innervated the most medial and ventral striatum (Fig. 5, compare $A, B$; Fig. 6, compare $A, B$ ). The extensive striatal denervation was associated with nearcomplete absence of TH-positive preterminal axons in the GP (Fig. 6, compare $A, B$ ) and was also apparent in the internal capsule and the MFB (Fig. 7, compare $A, B$ ).

rAAV-mediated GDNF expression had significant neuroprotective effects on TH-positive cells in the substantia nigra pars compacta in all three rAAV-GDNF-treated groups (Fig. 8, inset). The protection was near complete $(91.2 \%)$ in the SN group (Fig. $8 C$ ), $56.8 \%$ in the STR group (Fig. $8 D$ ), and $78.6 \%$ in the $\mathrm{SN}+\mathrm{STR}$ group (Fig. 8E). All animals in the $\mathrm{SN}$ and $\mathrm{SN}+\mathrm{STR}$ groups displayed extensive sprouting of TH-positive fibers dorsal and rostral to the nigra, surrounding the vector injection site, leading to disorganization of fibers at the level of MFB (Fig. 7C, $E)$. This extensive sprouting response also extended into the subthalamic nucleus, the entopeduncular nucleus (EP), and the ventral thalamus, but failed to reach the striatum (Figs. 5C, 6C).

In the STR group, substantial TH-positive sprouting was observed within the GP that also innervated the adjacent areas of the striatum (Fig. 6D). The sprouting fibers predominantly innervated the caudal and ventral parts of the striatum extending dorsally to the central striatum, whereas the dorsal and lateral striatal regions remained denervated (Fig. 5D). This sprouting response was much less pronounced in the $\mathrm{SN}+\mathrm{STR}$ group and completely absent in the SN group. In addition to this sprouting response in the STR group, the TH-positive fibers leaving the substantia nigra and entering the MFB were relatively normal in appearance (Fig. 7, compare $A, D$ ) compared with all the other rAAV-GDNF-treated groups (Fig. 7, compare $D, C, E$ ). At the level of the GP (Fig. 6D), in addition to the disorganized densely stained sprouting TH-positive fibers, TH-positive fibers with normal appearance and organization could also be observed in the myelinated fiber bundles of the internal capsule. This subpopulation of normal striatofugal TH-positive fibers was not observed in the other experimental groups (Fig. $6 B, C, E$ ). These observations suggest that in the STR group, lesion-induced retrograde axon degeneration did not progress caudally past the GP.

Densitometry measurements (Fig. 5, inset) showed a significant increase of striatal TH innervation in the STR group compared with all other treatment groups, from $\sim 10 \%$ of normal in the most denervated caudal regions of the lesioned controls to $\sim 25-$ $30 \%$ of normal in the rAAV-GDNF-injected animals.

\section{Expression of GFP in the nigra and striatum}

One of the control groups, killed at 6 months after injection, was injected with the rAAV-GFP vector to serve as a control for transduction. Immunohistochemistry for GFP confirmed the earlier observation (Klein et al., 1998) that the transduction efficiency of the rAAV vector is relatively high in substantia nigra and relatively lower in striatum in comparison (Fig. 9, compare $A$, $D)$. In the striatum, GFP-positive cells were observed adjacent to the injection site to a width of $\sim 300 \mu \mathrm{m}$ (Fig. $9 A, B$ ), and at least $90 \%$ of these cells had a neuron-like morphology that appeared to be both medium-sized spiny and aspiny neurons commonly found in striatum (Fig. 9B). Surprisingly, although the transduction in the striatum was confined to a small area, many of the GP neurons, $>1 \mathrm{~mm}$ distal to the caudal injection site of the vector, were also GFP positive (Fig. 9A,C).

In the nonlesioned animals injected with the rAAV-GFP vector (Fig. 9D,E), many GFP-positive neurons were observed in the substantia nigra, most prominently in the pars compacta. The vast majority of the transduced cells were neuronal in appearance, and the transduction extended $\sim 1.5 \mathrm{~mm}$ medial-lateral from the injection site within the substantia nigra. Of the GFP immunoreactive cells within the pars compacta, most were morphologically indistinguishable from normal nigral DA neurons (Fig. 9E). The observed nigral DA neuron and pallidal tropism of rAAV transduction is consistent with a higher degree of FGFr-1 expression [FGFr-1 is the putative receptor for rAAV internalization (Qing et al., 1999)] in these anatomical regions (Matsuo et al., 1994). In the 6-OHDA-lesioned animals that received the injection of the same vector, only a few GFP-expressing cells were found in pars compacta. In adjacent midbrain areas, however, similar numbers 
A. Cylinder test (3 wks p.l.)

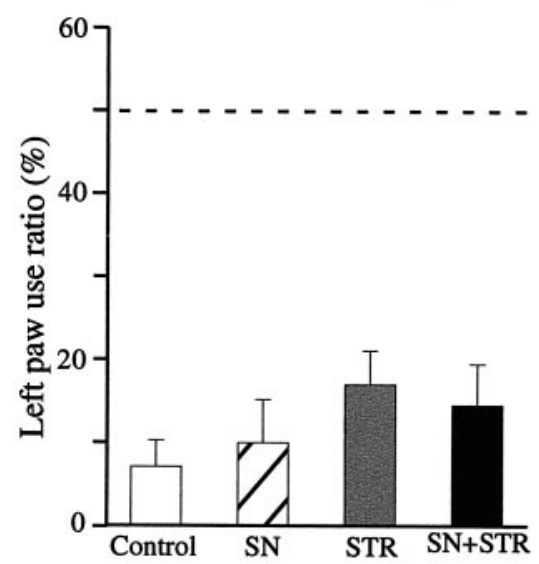

B. Cylinder test (23 wks p.l.)

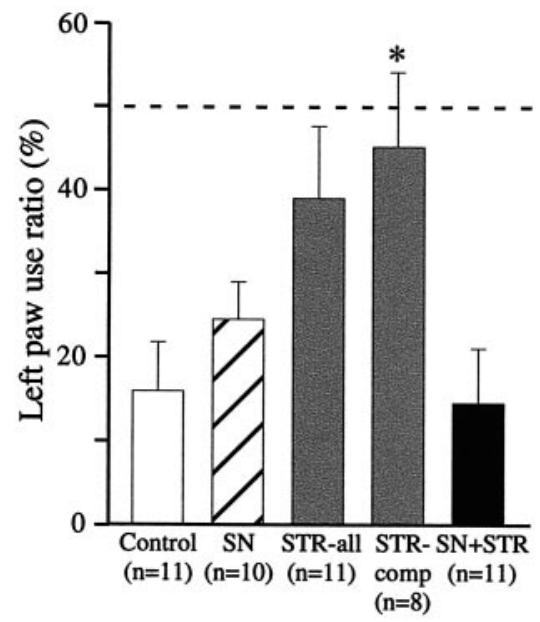

C. Contralateral paw

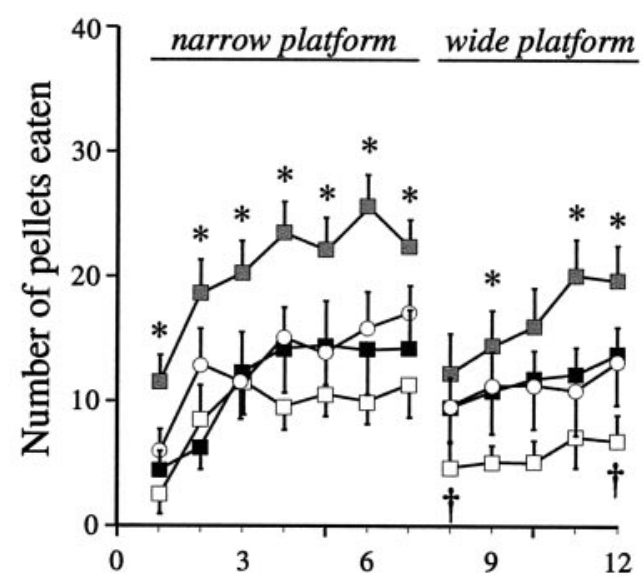

D. Ipsilateral paw

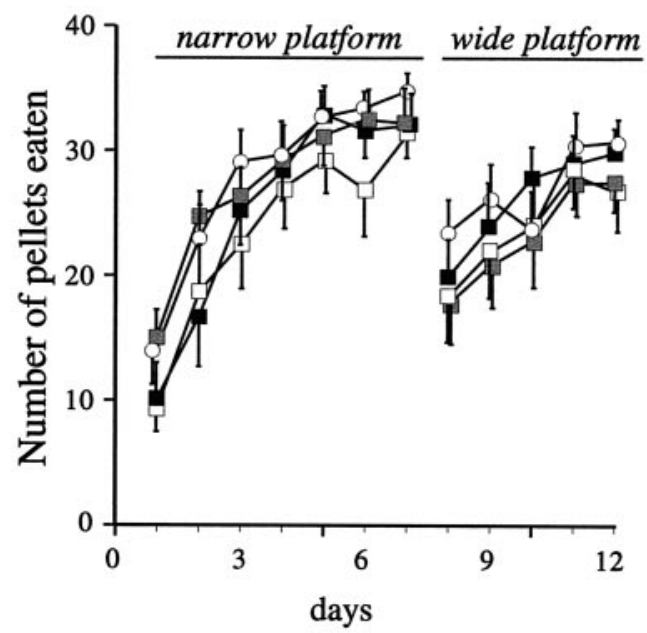

\section{E. Left forelimb stepping}

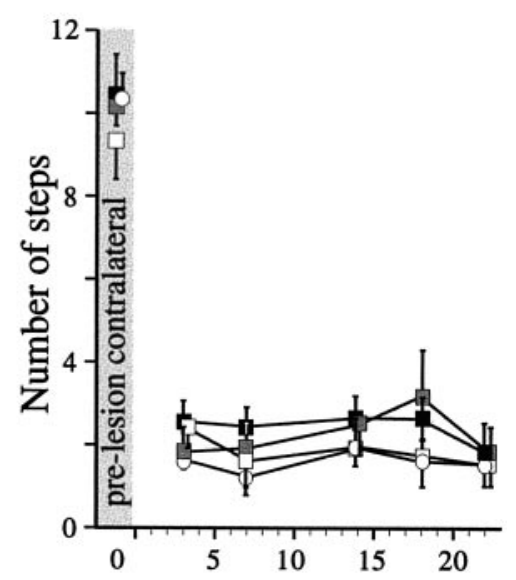

F. Right forelimb stepping

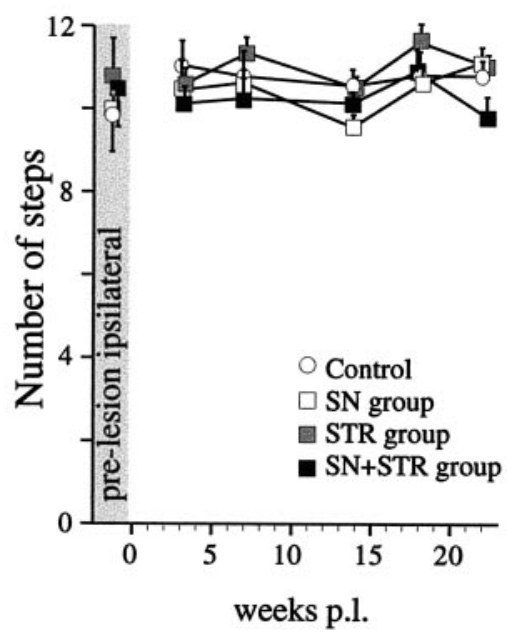

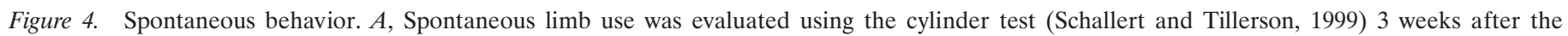

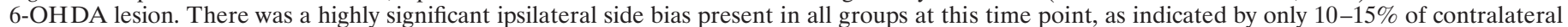

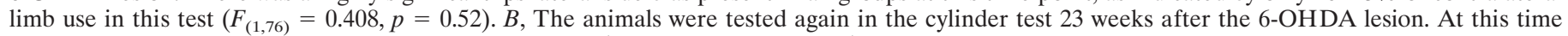

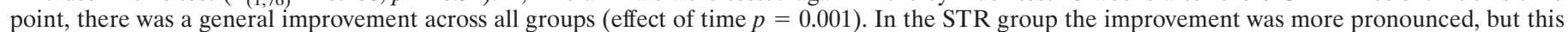

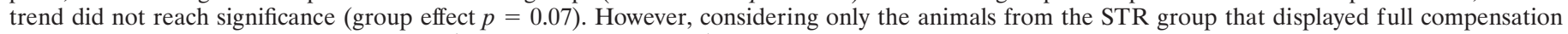

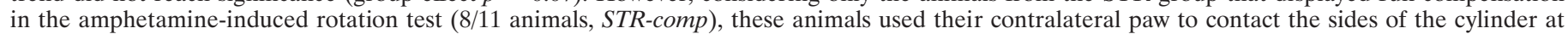

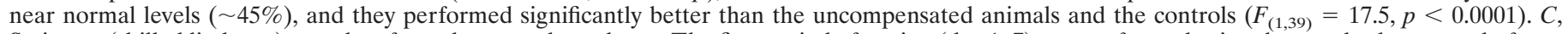

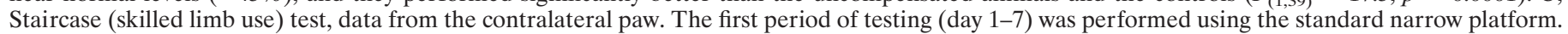

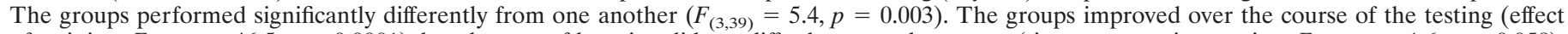

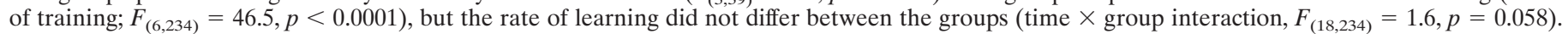

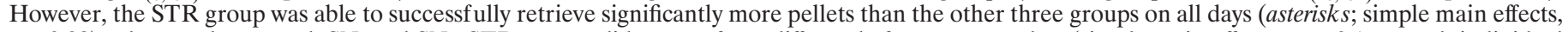

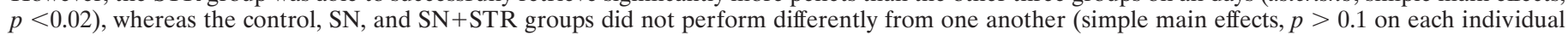

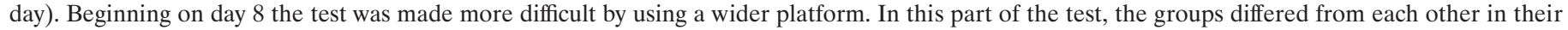

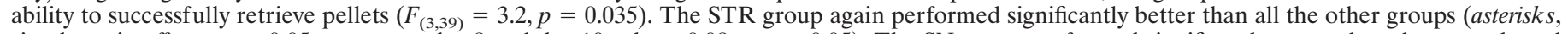

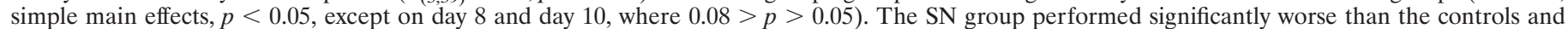

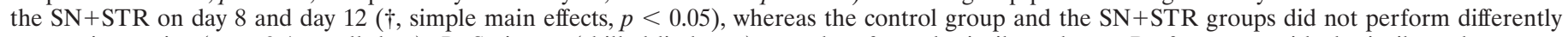

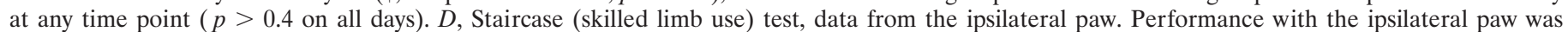

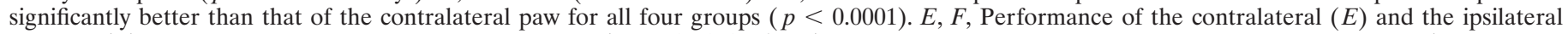

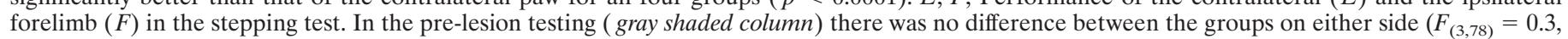

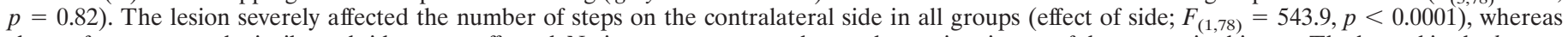

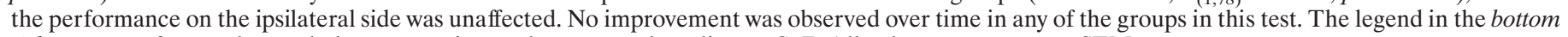
right corner refers to the symbols representing each group and applies to $C-F$. All values are means $\pm \mathrm{SEM}$.

of transduced cells were observed as in the unlesioned control animals, which is consistent with the fact that both dopaminergic and nondopaminergic neurons outside the substantia nigra (e.g., the A8 cell group) are spared by the 6-OHDA lesion (data not shown). In one of the GFP-transduced intact rats, GFP-positive fibers could be traced from the substantia nigra, along the length of the nigrostriatal pathway, into the striatum where they were seen to ramify into patches of fine GFP-positive terminals (Fig. $9 F, G)$. This pattern of GFP immunoreactivity after a nigral GFP transduction suggests that the GFP protein was anterogradely 

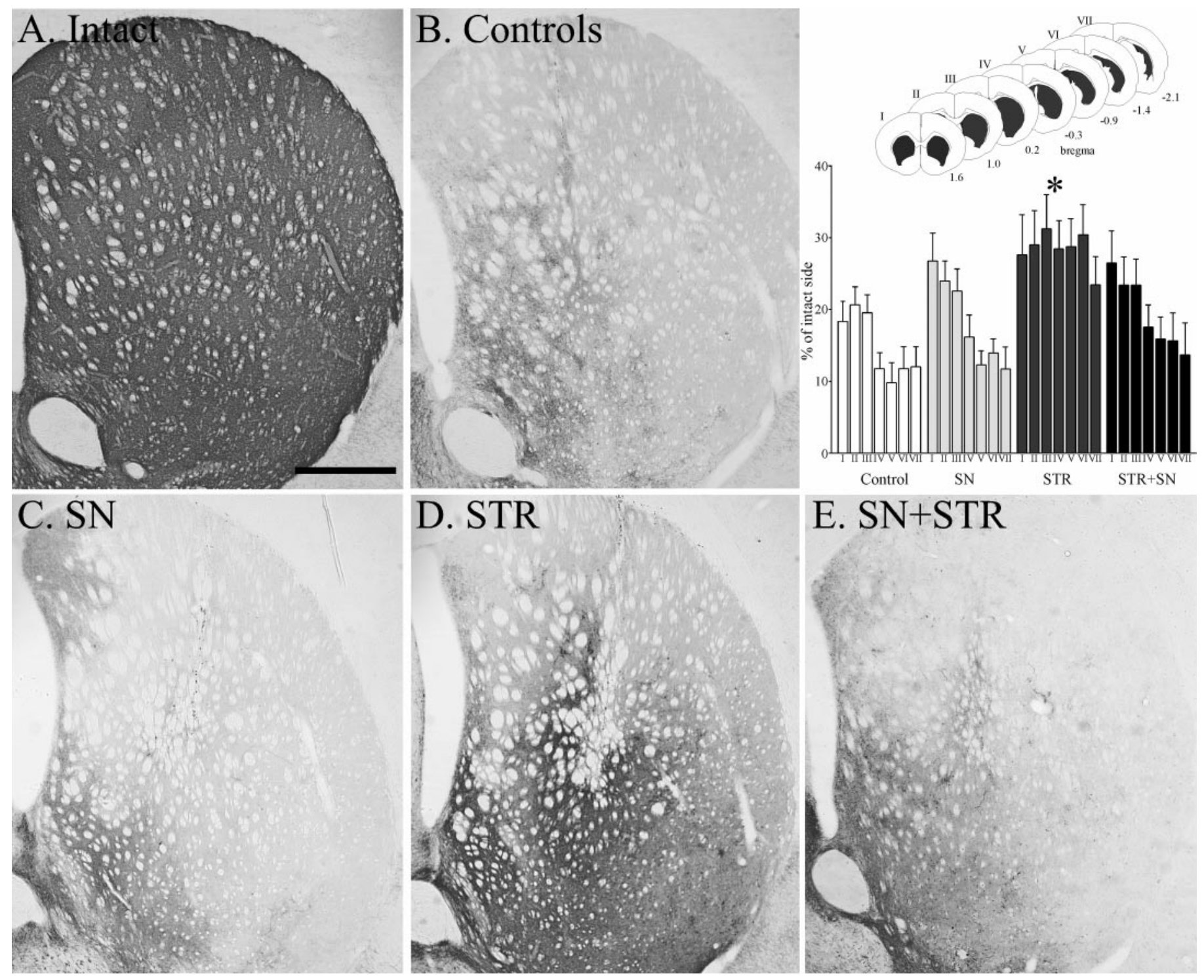

Figure 5. TH immunocytochemical staining of the central striatum. The 6-OHDA lesion resulted in degeneration of the TH-positive fibers in the controls $(B)$. Note the higher intensity of TH-positive fiber innervation in the STR $(D)$ group. The innervation in the $\mathrm{SN}(C)$ and $\mathrm{SN}+\mathrm{STR}(E)$ groups was not different from the controls. The scale bar in $A$ represents $500 \mu \mathrm{m}$ and applies also to photomicrographs in $B-E$. The inset shows the density of TH-positive fibers in the striatum measured at seven rostrocaudal levels, as shown in sketch. The 6-OHDA lesion induced extensive degeneration of the striatal TH-positive innervation in the control group. There was a highly significant difference in striatal TH-positive fiber density between the groups $\left(F_{(3,273)}=18.6, p<0.0001\right)$. Anterior regions (level I-III) were relatively more spared compared with posterior regions (levels IV-VII) across all groups $\left(F_{(6,273)}=5.2, p<0.0001\right)$. However, there was not a significant level $\times$ group interaction $\left(F_{(18,273)}=0.60, p=0.92\right)$; therefore, post hoc tests between groups were performed regardless of level. The STR group displayed significantly higher TH fiber density across all rostrocaudal levels compared with all other groups $\left({ }^{*} p<0.05\right.$; Tukey HSD). All values are means \pm SEM.

transported to the terminals in striatum, which is in agreement with the high levels of GDNF protein levels measured in the striatum in the SN group (Table 2).

In contrast to the 6-OHDA injection sites that appeared as small circumscribed scars at the 6 month time point, the rAAV vector injection sites were without signs of any nonspecific damage. This suggests low nonspecific toxicity of rAAV injections; this issue will be examined in greater detail in a later study.

\section{Distribution of GDNF immunoreactivity in the basal ganglia}

Immunohistochemisty was used to visualize the distribution of the GDNF protein 6 months after the injection of the vector (Fig. 10). The GDNF immunoreactivity observed in the striatum near the area of transduction was mainly extracellular (with some exceptions; see below) and was present in neither vector-injected controls nor the contralateral hemisphere of any brain (data not shown). In the STR (Fig. 10 $A$ ) and SN+STR (Fig. 10C) groups, there was a wide distribution of the GDNF protein within the striatum, extending into the deep layers of the cortex laterally (Fig. 10A,C,D,F). Caudally, the area of GDNF immunoreactivity extended into the GP in both groups (Fig. 10D, F). In general, the $\mathrm{SN}+\mathrm{STR}$ group displayed a wider distribution of GDNF immunoreactivity at all rostrocaudal levels. Strongly immunoreactive cellular profiles were observed in the most ventrolateral part of the striatum, in the adjacent cortex (Fig. 10C, $M$ ) and in the GP (Fig. 10F,N). Because these strongly GDNF-positive 

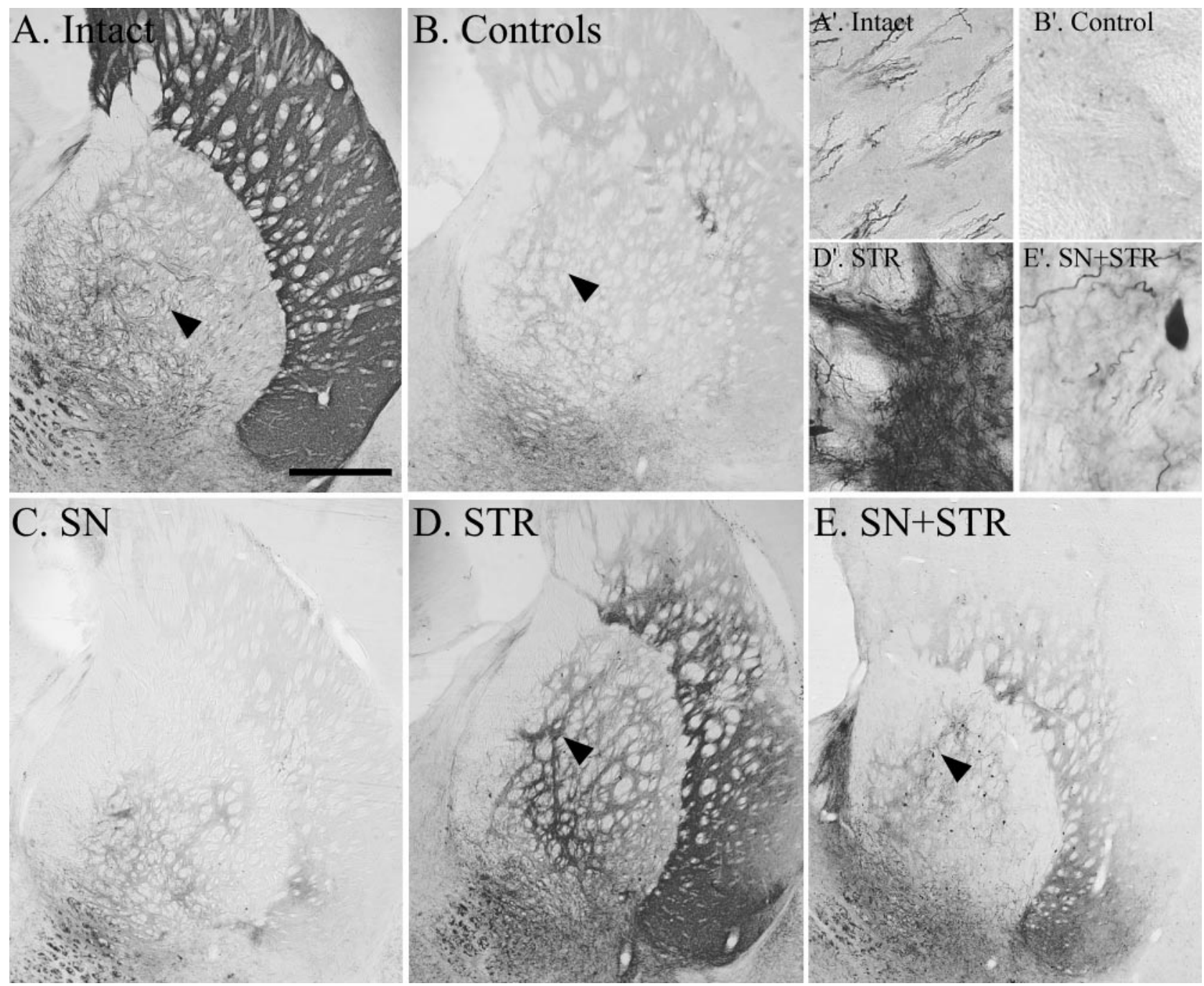

Figure 6. TH immunocytochemical staining of the globus pallidus and the caudal sectors of the lateral striatum. Normal preterminal axons passing through the GP (as in $A$ ) are lost in the controls $(B)$. Note the sprouting in the STR group within the both GP and striatum $(D)$. In the SN+STR group a less intense sprouting was observed in the GP $(E)$ and was completely absent in the SN group $(C)$. Arrowheads point to the area shown in high power adjacent to the individual figures. The scale bar in $A$ represents $500 \mu \mathrm{m}$ and applies also to photomicrographs in $B-E$.

cells (Fig. 10C,M) were distal to the vector injection site and these areas were not transduced in animals receiving identical injections of the rAAV-GFP vector, it is likely that these cells had accumulated GDNF released from transduced cells that were localized closer to the site of vector injection. Using an antibody to the GFR $\alpha$-1 receptor (Trupp et al., 1997; Kokaia et al., 1999), adjacent sections were examined for GFR $\alpha-1$ staining. Strongly GFR $\alpha$-1-immunoreactive cells were found precisely in the areas corresponding to those containing the GDNF-positive cells, suggesting that the accumulation of GDNF into these cells may be receptor mediated. The cellular GFR $\alpha-1$ staining was much stronger in the vector-injected hemisphere (data not shown).

In striatally transduced animals, GDNF immunoreactivity could be observed also in more caudal striatal efferent structures, including the EP (Fig. 10G, I) and the substantia nigra pars reticulata (Fig. 10J,L), on the injected side. In the pars reticulata, GDNF-positive cellular profiles were observed (Fig. 10K,L,O). These observations are highly consistent with anterograde transport of striatal rAAV-produced GDNF from the striatum caudally along the striatal efferent pathways.
In animals that received nigral rAAV-GDNF transductions (SN and $\mathrm{SN}+\mathrm{STR}$ groups), GDNF immunoreactivity was prominent in and around the substantia nigra (Fig. 10K). In the SN group, GDNF protein could be observed in the MFB at the level of the EP (Fig. 10H,I). However, no GDNF immunoreactivity was observed in the striatum or the GP (Fig. 10B,E) of SNtransduced animals.

\section{DISCUSSION}

The results show that the rAAV vector system can express the GDNF protein long-term at functionally efficient levels in the nigrostriatal system, in both the striatum and the substantia nigra. Transduction was six- to sevenfold higher in the substantia nigra than in the striatum. In agreement with previous findings (Klein et al., 1998), the rAAV-GFP vector labeled larger numbers of cells in the substantia nigra region than in the striatum, and $>90 \%$ of the transduced cells were neurons. In the mesencephalon, GFP was expressed preferentially in the substantia nigra pars compacta, and anterograde transport of the GFP protein was observed along the axons of the nigrostriatal pathway and in 

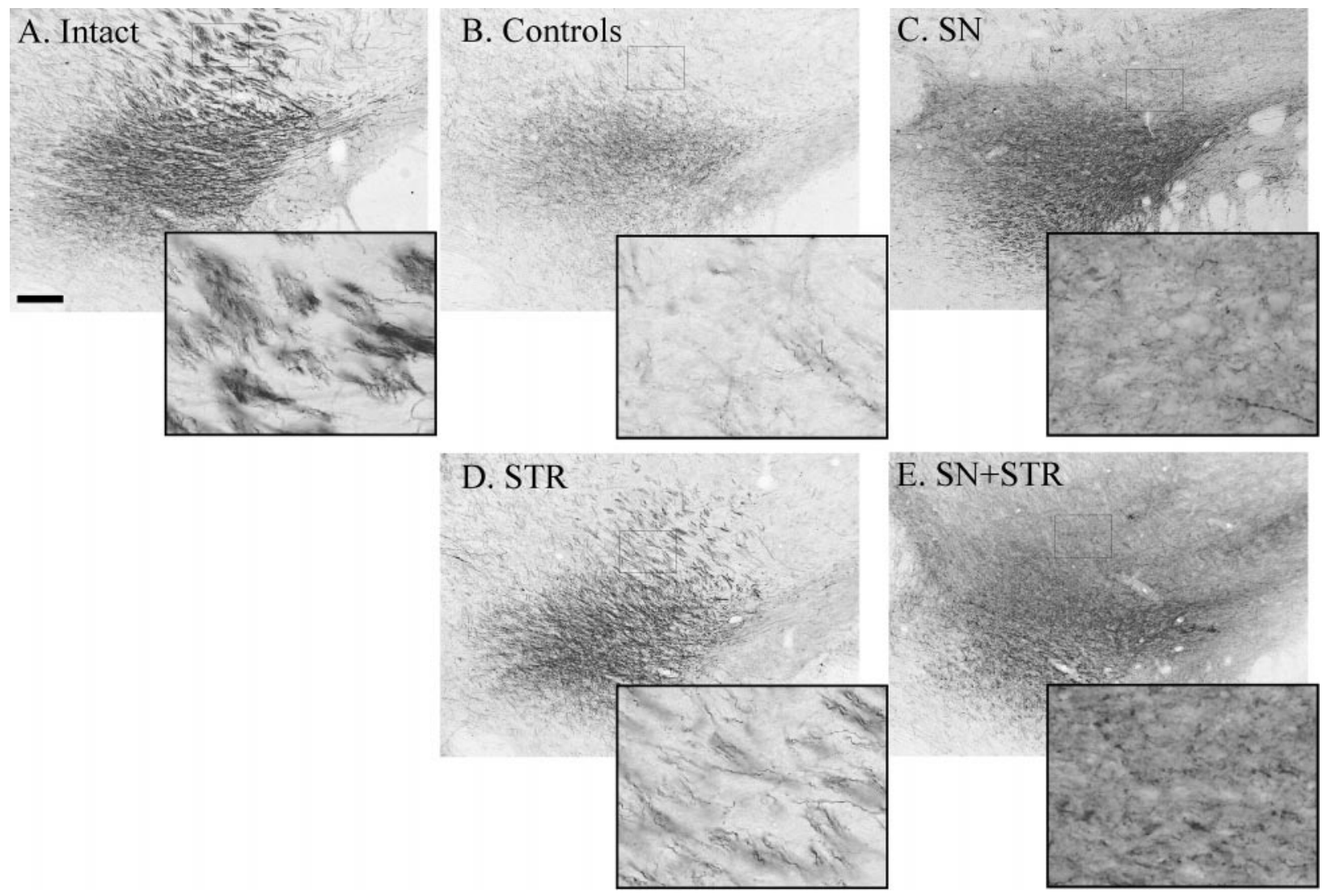

Figure 7. TH immunocytochemical staining of the MFB. TH-positive axons are observed in bundles in the untreated brain $(A)$. Most of the axons placed dorsally in the bundle are lost because of the lesion $(B)$. Note the abnormal sprouting in the $\mathrm{SN}$ and $\mathrm{SN}+\mathrm{STR}$ groups $(C, E)$ and the preservation of the normal pattern in the STR group $(D)$. Rectangles indicate the area shown in high power adjacent to the individual figures. Scale bar (shown in A): $A-E, 500 \mu \mathrm{m}$.

terminals within the striatum. The transgenic GDNF was widely distributed extracellularly up to a distance of $\sim 2 \mathrm{~mm}$ from the production site, which is consistent with GDNF being a secreted protein and able to diff use widely within the host tissue. Moreover, in the rats receiving injections of rAAV-GDNF in the striatum, GDNF was effectively transported anterogradely along the striatonigral pathway to GP, EP, and substantia nigra. Anterograde transport along the nigrostriatal pathway, from substantia nigra to striatum, is suggested by the ELISA measurements; the absence of GDNF immunoreactivity in the striatum in the SN group indicates that staining was completely abolished in the 6-OHDA-lesioned rats.

\section{Functional impact on the intact nigrostriatal DA system}

rAAV-GDNF injections in the substantia nigra provide a tool to express GDNF preferentially within the DA neurons themselves. In the striatum, by contrast, the vector was expressed in the neuronal targets of the nigrostriatal pathway. Overexpression of GDNF by the rAAV-GDNF vector in either site induced functional effects in the intact nigrostriatal DA system, observed as spontaneous motor asymmetry in animals receiving vector injections in the nigra, and a high rate of amphetamine-induced turning in animals injected in either substantia nigra or striatum. Increased striatal DA turnover was found in all groups, and increased striatal DA synthesis was seen in the SN+STR group. These data suggest that long-lasting activation of DA turnover in the intact nigrostriatal system can be achieved by overexpression of GDNF in the DA neurons themselves or by GDNF secretion from cells in the striatal target area. Interestingly, forelimb stepping was unaffected in these rats, suggesting that overexpression of GDNF unilaterally in the intact nigrostriatal system did not interfere with normal motor function.

\section{Protection of DA neurons against the toxic damage}

Significant rescue of nigral DA neurons was obtained with rAAVGDNF injection in either substantia nigra or striatum. This effect was most pronounced in the animals receiving vector injections in the substantia nigra, and the magnitude of cell protection appeared to match the level of GDNF expressed in the nigral region, as measured by ELISA at the time of 6-OHDA injection. In the SN group, we observed near-complete (91\%) protection with a GDNF tissue level of $\sim 1.4 \mathrm{ng} / \mathrm{mg}$ (which represents a 15to 20-fold increase over the endogenous GDNF concentration) (Table 2). This suggests that overexpression of GDNF within the DA neurons themselves is particularly efficient for the rescue of the nigral cell bodies after 6-OHDA-induced axotomy. In a previous study (Choi-Lundberg et al., 1997), GDNF was expressed in the nigral region with an adenoviral vector. In this case, only partial protection was obtained, despite a tissue level of GDNF that was severalfold higher than in the present experiment. This difference may be explained by the fact that the adenoviral vector is expressed mainly outside the DA neurons and that GDNF in this case is likely to act in a less efficient, paracrine manner. Indeed, infusion of GDNF protein, over the substantia nigra at a dose of $2.5-3 \mu \mathrm{g} / \mathrm{d}$, gives only $60-70 \%$ 

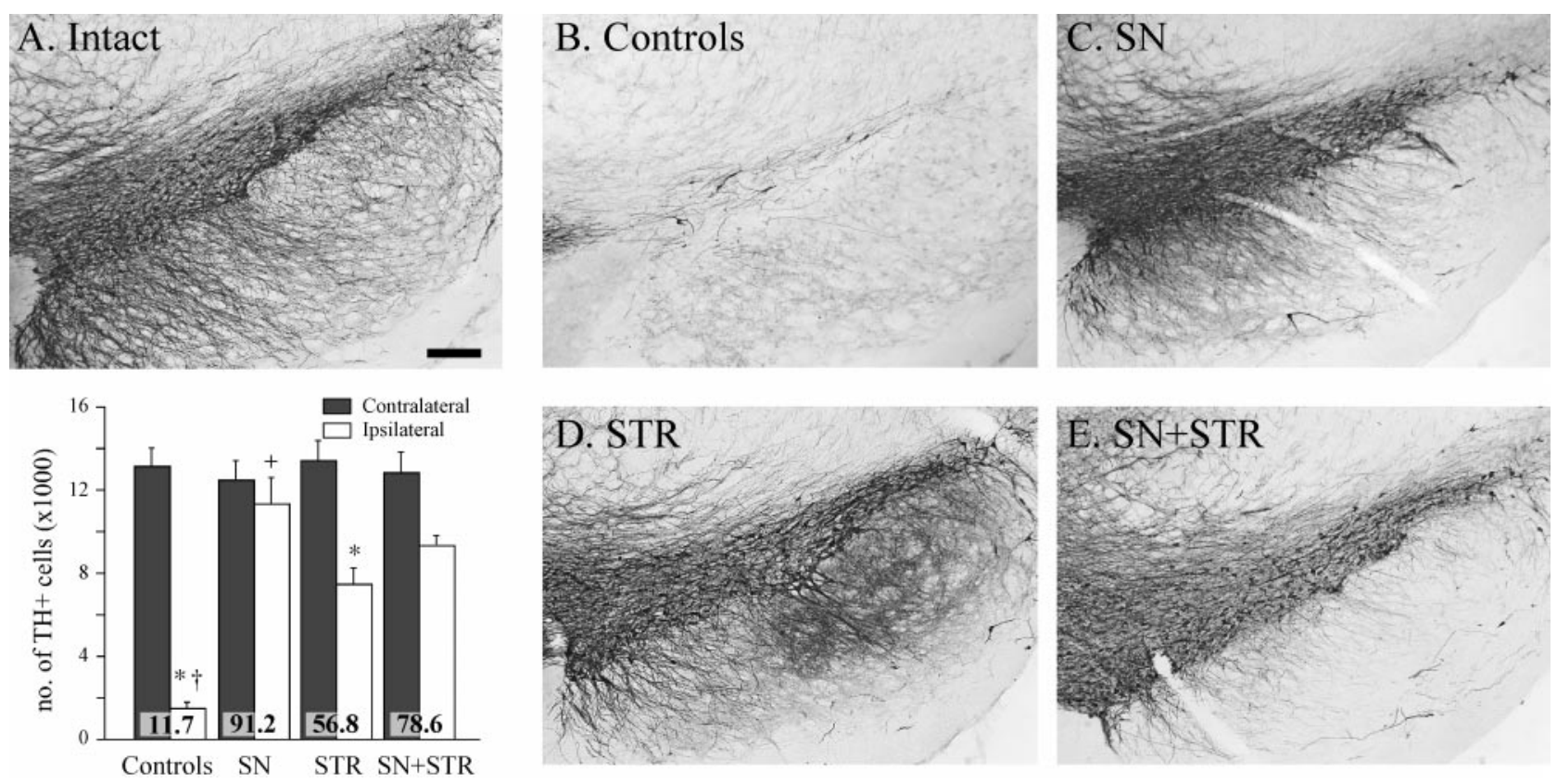

Figure 8. TH immunocytochemical staining of the cell bodies in the substantia nigra. Note the protection of the TH-positive cell bodies in the pars compacta in all GDNF vector-injected groups $(C-E)$ compared with the lesioned control $(B)$. Scale bar (shown in $A): A-E$, $500 \mu \mathrm{m}$. The inset shows the TH-positive cell numbers in the substantia nigra estimated at 27 weeks after lesion using stereological counting methods as described in Materials and Methods. In the untreated hemisphere, TH-positive cell numbers were closely similar in all four groups $(p>0.99)$. The 6-OHDA lesion resulted in $\sim 88 \%$ reduction in the $\mathrm{TH}+$ cells in the control group. There was a significant protection of nigral TH-positive cells in all rAAV-GDNF-treated groups (ANOVA, followed by post hoc Tukey HSD tests, $p<0.0001$ ): 91 and 78\%, respectively, in the SN and SN+STR groups (Tukey HSD tests, $p>0.99$ ). The protection of TH-positive cells in the STR group was significantly less, at $57 \%$ (Tukey HSD tests, $p<0.05$ ), but the TH-positive nigral cell survival was still highly significant compared with controls. ${ }^{*} p<0.0001$ different from intact side; ${ }^{+} p<0.0001$ different from all other groups. The values inside the bars indicate percentage TH-positive cells compared with the intact side. All values are means \pm SEM.

survival in 6-OHDA-lesioned animals (Lu and Hagg, 1997; Rosenblad et al., 2000b).

Injection of GDNF protein into the striatum is effective in protecting nigral DA neurons when given before or soon after the 6-OHDA lesion (Kearns et al., 1997; Rosenblad et al., 1999; Kirik, Rosenblad, and Björklund, unpublished observations). In the present experiment, rAAV-GDNF injections into the striatum had a highly significant, but incomplete, protective effect on the DA cells. This suggests that GDNF delivered at the level of the axon terminals may be as efficient as delivery at the level of the cell bodies. However, higher levels and/or a greater spread of GDNF throughout striatum may be required for complete nigral cell protection.

\section{Regeneration and functional recovery}

The acute behavioral impairment seen in all rAAV-GDNFinjected groups indicates that overexpression of GDNF, at the levels obtained here, were not sufficient to protect the striatal DA terminals against the acute toxic damage. In the SN group, no functional recovery was seen despite near-complete protection of the DA cell bodies. This is consistent with previous studies using intranigral injections of GDNF showing that sparing of nigral DA neurons in the absence of a functional striatal innervation is insufficient for functional recovery in the intrastriatal 6-OHDA lesion model (Winkler et al., 1996; Rosenblad et al., 2000b). Massive sprouting of TH-positive fibers occurred in and around the MFB, close to the rescued DA cell bodies in substantia nigra. The meshwork of fibers was seen to extend rostrally up to the border of the GP, overlapping with the distribution of the GDNF immunoreactivity. The extent of denervation in the striatum and loss of axons along the pathway were similar to that of the lesioned controls, suggesting that expression of GDNF in the nigral cells was unable to direct any axonal regeneration into the striatal target.

In the STR group, sprouting and regeneration were abundant in the GP and the caudal and ventral striatum, and the THpositive axons along the nigrostriatal pathway were partly preserved. From the distribution of sprouting fibers, it appears that the continuous expression of GDNF had promoted the regrowth of TH-positive fibers from the axon endings in the GP and extending into the striatum. Thus, the efficient striatal reinnervation seen in the STR group is likely to be caused by a combination of a partial protection of the lesioned nigrostriatal axons followed by regeneration into the region of high GDNF expression. This is consistent with the time course of functional recovery in the STR group, which was delayed in onset and developed progressively over the first 4-5 months after the lesion, as seen in amphetamine rotation and the staircase and cylinder tests. The aberrant pallidostriatal TH innervation pattern in the STR group (Fig. $6 A^{\prime}$, $D^{\prime}$ ), coupled with the protracted time course of the recovery, unequivocally demonstrates remodeling of the nigrostriatal tract rather than a GDNF-induced reexpression of the TH enzyme in the nigrostriatal DA system.

The increased striatal TH-positive innervation seen in the STR group did not occur in the $\mathrm{SN}+\mathrm{STR}$ group. This difference may be attributable to the intense local sprouting induced by overexpression of GDNF in the nigra that may have prevented regeneration of the lesioned axons toward the striatal source of GDNF. If so, expression of GDNF in the nigral DA neurons themselves may be detrimental, rather than positive, for the ability of the lesioned nigrostriatal fibers to regenerate and reinnervate the 


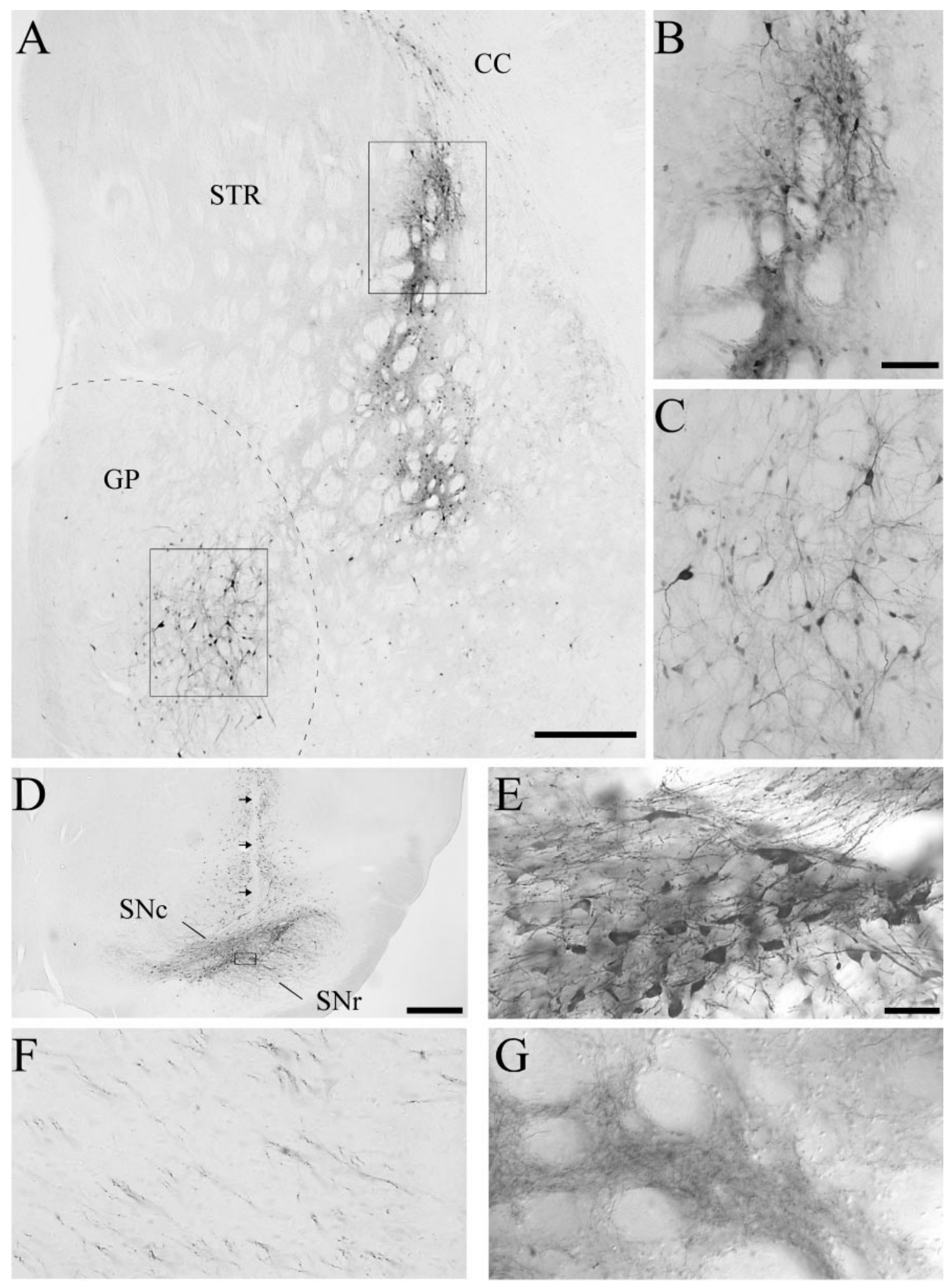

Figure 9. Examples of rAAV-GFP transductions in lesioned and unlesioned animals. $A$, Lesioned control, 6 months survival; rAAV-GFP transduction from a single injection site in posterior striatum. GFP-positive cells are apparent in both the striatum and the GP. The box in the striatum $(S T R)$ indicates the area of enlargement shown in $B$, and the box in the $G P$ indicates the area of enlargement shown in $C$. Scale bar, $500 \mu \mathrm{m}$. $C C$, Corpus callosum. $B$, GFP-expressing cells with neuronal morphology along the injection tract. Scale bar, $100 \mu \mathrm{m}$. $C$, GFP-positive neurons in the GP, distal to the injection site (scale bar as in $B$ ). $D$, rAAV-GFP transduction in the substantia nigra from an intact animal (4 weeks survival). There is transduction throughout the substantia nigra pars compacta $(S N c)$ as well as dorsally along the needle track (arrows). SNr, Substantia nigra, pars reticulata. The box indicates the area of enlargement in $E$. Scale bar, $500 \mu \mathrm{m}$. E, The GFP-positive cells in this higher magnification are morphologically consistent with substantia nigra pars compacta DA neurons. Scale bar (shown in $E$ ): $E-G, 50 \mu \mathrm{m}$. F. GFP-positive fibers could be traced along the length of the nigrostriatal pathway in the same animal. These fibers were observed to ramify into patches of fine GFP-positive terminals in the striatum $(G)$. 

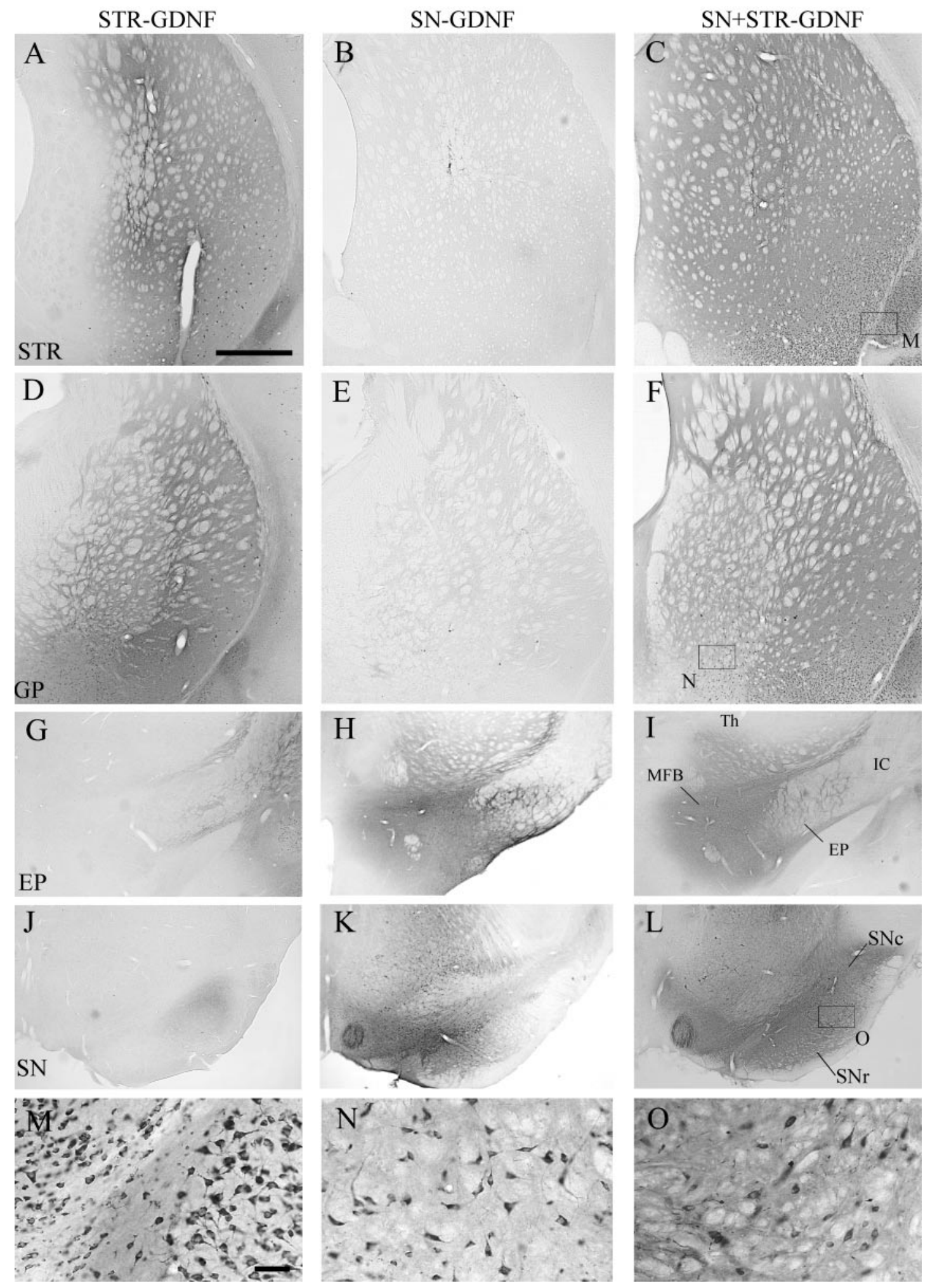

Figure 10. GDNF immunoreactivity, 6 months after vector injection, is illustrated at four levels in the STR $(A, D, G, J)$, SN $(B, E, H, K)$, and $\mathrm{SN}+\mathrm{STR}$ $(C, F, I, L)$ groups, taken from the same specimen in each group. The most anterior level $(A-C)$ illustrates a central striatal region. Note the diffuse extracellular staining and immunoreactive cellular profiles in the ventral striatum and the adjacent cortex in the STR and SN+STR groups $(A, C)$. The next posterior level $(D-F)$ illustrates the GP and caudal striatum. Similarly, in striatally transduced animals GDNF immunoreactivity covers both the striatum and GP $(B, F)$. GDNF-positive cellular profiles are observed in both the striatum $(C, M)$ and the GP $(F, N)$ of the SN+STR group. In the SN group, both the central and caudal striatum as well as the GP are devoid of GDNF immunoreactivity $(B, E)$. At the level of the EP $(G-I)$, GDNF immunoreactivity is observed in the EP in the STR group $(G)$, in the ventral thalamus $(T h)$ in the SN group $(H)$, and in the MFB, Th, and EP in the SN+STR group $(I)$. Note the staining restricted to the reticulata $(S N r)$ in the STR group $(J)$, and the more widespread staining in the SN and SN+STR groups $(K, L)$. The box in $C$ indicates the area of enlargement shown in $M$, the box in $F$ indicates the area of enlargement in $N$, and the box in $L$ indicates the area of enlargement shown in $O$. IC, Internal capsule. Scale bars: $A-F, 1 \mathrm{~mm} ; G-L, 750 \mu \mathrm{m} ; M, 50 \mu \mathrm{m}$ (applies also to $N, O$ ). 
denervated striatum. The absence of any significant functional recovery in the $\mathrm{SN}+\mathrm{STR}$ group is in line with this interpretation.

\section{Conclusion}

In this experiment, three independent biological actions of GDNF on the nigrostriatal DA neurons have been demonstrated: first, an upregulation of DA synthesis and turnover in intact nigral neurons leading to spontaneous and drug-induced asymmetries; second, a protection of nigral DA cells against toxin-induced cell death; and third, functional regeneration and reinnervation of the nigrostriatal pathway. The results demonstrate that the rAAV vector system can be used to express GDNF at biologically efficient levels both in the nigrostriatal DA neurons and in their neuronal targets in the striatum. Although transduction at both of these sites afforded significant rescue of the lesioned nigral DA cell bodies, only GDNF expression in the striatum was able to preserve the integrity of the projecting axons, stimulate reinnervation of the denervated striatum, and promote functional recovery in the intrastriatal 6-OHDA lesion model. This suggests that GDNF acting in an autocrine manner is highly efficient in preserving the integrity of the nigral cell bodies. However, expression of GDNF within the DA neurons themselves was unable to sustain the lesioned axons or induce any striatal reinnervation or functional recovery. Target-derived GDNF expression, by contrast, was less efficient in protecting the nigral cell bodies but had a prominent long-term stimulatory effect on degeneration and reinnervation of the initially denervated striatum, accompanied by significant recovery in both drug-induced and spontaneous motor behaviors. After nigral transduction, extensive sprouting was observed close to the DA cell bodies. This local sprouting, however, was detrimental rather than beneficial in that it seemed to impair function and block striatal regeneration in animals receiving vector injections in both the substantia nigra and striatum.

$\mathrm{PD}$ is a degenerative disorder of the dopaminergic nigrostriatal system that can progress over years (Fearnley and Lees, 1991; Morrish et al., 1996). In PD, as in the intrastriatal 6-OHDA lesion model, striatal DA innervation appears to degenerate before the death of the nigral cell bodies (McGeer et al., 1988; Fearnley and Lees, 1991; Gibb and Lees, 1994). Indeed, when $70-80 \%$ of striatal DA is depleted and PD symptoms begin to manifest themselves, only $\sim 50 \%$ of the DA cell bodies have been lost (Fearnley and Lees, 1991; Gibb and Lees, 1994). These data suggest that nigral DA neurons may survive for some time without an intact functional nigrostriatal projection. If so, the present data imply that the striatum, rather than the nigra, should be the primary target for gene transfer of GDNF early in PD.

\section{REFERENCES}

Bartlett JS, Samulski RJ, McCown TJ (1998) Selective and rapid uptake of adeno-associated virus type 2 in brain. Hum Gene Ther 9:1181-1186.

Beck KD, Valverde J, Alexi T, Poulsen K, Moffat B, Vandlen RA, Rosenthal A, Hefti F (1995) Mesencephalic dopaminergic neurons protected by GDNF from axotomy-induced degeneration in the adult rat. Nature 373:339-341.

Bilang-Bleuel A, Revah F, Colin P, Locquet I, Robert JJ, Mallet J, Horellou P (1997) Intrastriatal injection of an adenoviral vector expressing glial-cell-line-derived neurotrophic factor prevents dopaminergic neuron degeneration and behavioral impairment in a rat model of Parkinson disease. Proc Natl Acad Sci USA 94:8818-8823.

Björklund A, Rosenblad C, Winkler C, Kirik D (1997) Studies on neuroprotective and regenerative effects of GDNF in a partial lesion model of Parkinson's disease. Neurobiol Dis 4:186-200.

Bohn MC (1999) A commentary on glial cell line-derived neurotrophic factor (GDNF). From a glial secreted molecule to gene therapy. Biochem Pharmacol 57:135-142.

Choi-Lundberg DL, Lin Q, Chang YN, Chiang YL, Hay CM, Mohajeri H, Davidson BL, Bohn MC (1997) Dopaminergic neurons protected from degeneration by GDNF gene therapy. Science 275:838-841.

Choi-Lundberg DL, Lin Q, Schallert T, Crippens D, Davidson BL, Chang YN, Chiang YL, Qian J, Bardwaj L, Bohn MC (1998) Behavioral and cellular protection of rat dopaminergic neurons by an adenoviral vector encoding glial cell line-derived neurotrophic factor. Exp Neurol 154:261-275.

Cochran WG, Cox GM (1957) Experimental design. New York: Wiley. Connor B, Kozlowski DA, Schallert T, Tillerson JL, Davidson BL, Bohn MC (1999) Differential effects of glial cell line-derived neurotrophic factor (GDNF) in the striatum and substantia nigra of the aged Parkinsonian rat. Gene Ther 6:1936-1951.

Deglon N, Tseng JL, Bensadoun JC, Zurn AD, Arsenijevic Y, Pereira de Almeida L, Zufferey R, Trono D, Aebischer P (2000) Self-inactivating lentiviral vectors with enhanced transgene expression as potential gene transfer system in Parkinson's disease. Hum Gene Ther 11:179-190.

Fearnley JM, Lees AJ (1991) Ageing and Parkinson's disease: substantia nigra regional selectivity. Brain 114:2283-2301.

Gash DM, Gerhardt GA, Hoffer BJ (1998) Effects of glial cell linederived neurotrophic factor on the nigrostriatal dopamine system in rodents and nonhuman primates. Adv Pharmacol 42:911-915.

Gibb WRG, Lees AJ (1994) Pathological clues to the cause of Parkinson's disease. In: Movement Disorders 3 (Marsden CD, Fahn S, eds) pp 147-166. Oxford: Butterworth-Heinemann.

Gundersen HJG, Jensen EB (1987) The efficiency of systematic sampling in stereology and its prediction. J Microsc 147:229-263.

Horger BA, Nishimura MC, Armanini MP, Wang LC, Poulsen KT, Rosenblad C, Kirik D, Moffat B, Simmons L, Johnson Jr E, Milbrandt J, Rosenthal A, Björklund A, Vandlen RA, Hynes MA, Phillips HS (1998) Neurturin exerts potent actions on survival and function of midbrain dopaminergic neurons. J Neurosci 18:4929-4937.

Kaplitt MG, Leone P, Samulski RJ, Xiao X, Pfaff DW, O'Malley KL, During MJ (1994) Long-term gene expression and phenotypic correction using adeno-associated virus vectors in the mammalian brain. Nat Genet 8:148-154.

Kearns CM, Cass WA, Smoot K, Kryscio R, Gash DM (1997) GDNF protection against 6-OHDA: time dependence and requirement for protein synthesis. J Neurosci 17:7111-7118.

Kirik D, Rosenblad C, Björklund A (1998) Characterization of behavioral and neurodegenerative changes following partial lesions of the nigrostriatal dopamine system induced by intrastriatal 6-hydroxydopamine in the rat. Exp Neurol 152:259-277.

Kirk RE (1968) Experimental design: procedures for the behavioral sciences. Belmont, CA: Brooks/Cole.

Klein RL, Meyer EM, Peel AL, Zolotukhin S, Meyers C, Muzyczka N, King MA (1998) Neuron-specific transduction in the rat septohippocampal or nigrostriatal pathway by recombinant adeno-associated virus vectors. Exp Neurol 150:183-194.

Kokaia Z, Airaksinen MS, Nanobashvili A, Larsson E, Kujamaki E, Lindvall O, Saarma M (1999) GDNF family ligands and receptors are differentially regulated after brain insults in the rat. Eur $\mathrm{J}$ Neurosci 11:1202-1216.

Leff SE, Spratt SK, Snyder RO, Mandel RJ (1999) Long-term restoration of striatal L-aromatic amino acid decarboxylase activity using recombinant adeno-associated viral vector gene transfer in a rodent model of Parkinson's disease. Neuroscience 92:185-196.

Lo WD, Qu G, Sferra TJ, Clark R, Chen R, Johnson PR (1999) Adenoassociated virus-mediated gene transfer to the brain: duration and modulation of expression. Hum Gene Ther 10:201-213.

Lu X, Hagg T (1997) Glial cell line-derived neurotrophic factor prevents death, but not reductions in tyrosine hydroxylase, of injured nigrostriatal neurons in adult rats. J Comp Neurol 388:484-494.

Mandel RJ, Spratt SK, Snyder RO, Leff SE (1997) Midbrain injection of recombinant adeno-associated virus encoding rat glial cell linederived neurotrophic factor protects nigral neurons in a progressive 6-hydroxydopamine-induced degeneration model of Parkinson's disease in rats. Proc Natl Acad Sci USA 94:14083-14088.

Mandel RJ, Rendahl KG, Spratt SK, Snyder RO, Cohen LK, Leff SE (1998) Characterization of intrastriatal recombinant adeno-associated virus-mediated gene transfer of human tyrosine hydroxylase and human GTP-cyclohydrolase I in a rat model of Parkinson's disease. J Neurosci 18:4271-4284. 
Mandel RJ, Snyder RO, Leff SE (1999) Recombinant adeno-associated viral vector-mediated glial cell line-derived neurotrophic factor gene transfer protects nigral dopamine neurons after onset of progressive degeneration in a rat model of Parkinson's disease. Exp Neurol 160:205-214.

Matsuo A, Tooyama I, Isobe S, Oomura Y, Akiguchi I, Hanai K, Kimura J, Kimura H (1994) Immunohistochemical localization in the rat brain of an epitope corresponding to the fibroblast growth factor receptor-1. Neuroscience 60:49-66.

McCown TJ, Xiao X, Li J, Breese GR, Samulski RJ (1996) Differential and persistent expression patterns of CNS gene transfer by an adenoassociated virus (AAV) vector. Brain Res 713:99-107.

McGeer PL, Itagaki S, Akiyama H, McGeer EG (1988) Rates of cell death in parkinsonism indicate active neuropathological process. Ann Neurol 24:574-576.

Montoya CP, Campbell HL, Pemberton KD, Dunnett SB (1991) The "staircase test": a measure of independent forelimb reaching and grasping abilities in rats. J Neurosci Methods 36:219-228.

Morrish PK, Sawle GV, Brooks DJ (1996) An [18F]dopa-PET and clinical study of the rate of progression in Parkinson's disease. Brain 119:585-591.

Muzyczka N (1992) Use of adeno-associated virus as a general transduction vector for mammalian cells. Curr Top Microbiol Immunol 158:97-129.

Olsson M, Nikkhah G, Bentlage C, Björklund A (1995) Forelimb akinesia in the rat Parkinson model: differential effects of dopamine agonists and nigral transplants as assessed by a new stepping test. J Neurosci 15:3863-3875.

Paxinos G, Watson C (1998) The rat brain in stereotaxic coordinates, Ed 4. San Diego: Academic.

Peel AL, Zolotukhin S, Schrimsher GW, Muzyczka N, Reier PJ (1997) Efficient transduction of green fluorescent protein in spinal cord neurons using adeno-associated virus vectors containing cell type-specific promoters. Gene Ther 4:16-24.

Qing K, Mah C, Hansen J, Zhou S, Dwarki V, Srivastava A (1999) Human fibroblast growth factor receptor 1 is a co-receptor for infection by adeno-associated virus 2 . Nat Med 5:71-77.

Rosenblad C, Kirik D, Devaux B, Moffat B, Phillips HS, Björklund A (1999) Protection and regeneration of nigral dopaminergic neurons by neurturin or GDNF in a partial lesion model of Parkinson's disease after administration into the striatum or the lateral ventricle. Eur J Neurosci 11:1554-1566.

Rosenblad C, Gronborg M, Hansen C, Blom N, Meyer M, Johansen J, Dago L, Kirik D, Patel UA, Lundberg C, Trono D, Björklund A, Johansen TE (2000a) In vivo protection of nigral dopamine neurons by lentiviral gene transfer of the novel GDNF-family member Neublastin/Artemin. Mol Cell Neurosci 15:199-214.

Rosenblad C, Kirik D, Björklund A (2000b) Sequential administration of GDNF into the substantia nigra and striatum promotes dopamine neuron survival and axonal sprouting but not striatal reinnervation or functional recovery in the partial 6-OHDA lesion model. Exp Neurol 161:503-516.

Sauer H, Rosenblad C, Björklund A (1995) Glial cell line-derived neurotrophic factor but not transforming growth factor beta 3 prevents delayed degeneration of nigral dopaminergic neurons following striatal 6-hydroxydopamine lesion. Proc Natl Acad Sci USA 92:8935-8939.

Schallert T, Lindner MD (1990) Rescuing neurons from trans-synaptic degeneration after brain damage: helpful, harmful, or neutral in recovery of function? Can J Psychol 44:276-292.

Schallert T, Tillerson JL (1999) Intervention strategies for degeneration of dopamine neurons in Parkinsonism: optimising behavioral assessment of outcome. In: Innovative models of CNS disease: from molecule to therapy, pp 131-151. Clifton, NJ: Humana.

Schallert T, Norton D, Jones TA (1992) A clinically relevant unilateral rat model of Parkinsonian akinesia. J Neural Transpl Plast 3:332-333.

Schmidt RH, Ingvar M, Lindvall O, Stenevi U, Björklund A (1982) Functional activity of substantia nigra grafts reinnervating the striatum: neurotransmitter metabolism and [14C]2-deoxy-D-glucose autoradiography. J Neurochem 38:737-748.

Snyder RO, Xiao X, Samulski RJ (1996) Production of recombinant adeno-associated viral vectors. In: Current protocols in human genetics (Dracopoli N, Haines J, Krof B, eds) pp 1-24. New York: Wiley.

Sternberger LA, Hardy Jr PH, Cuculis JJ, Meyer HG (1970) The unlabeled antibody enzyme method of immunohistochemistry: preparation and properties of soluble antigen-antibody complex (horseradish peroxidase-antihorseradish peroxidase) and its use in identification of spirochetes. J Histochem Cytochem 18:315-333.

Sullivan AM, Opacka-Juffry J, Blunt SB (1998) Long-term protection of the rat nigrostriatal dopaminergic system by glial cell line-derived neurotrophic factor against 6-hydroxydopamine in vivo. Eur J Neurosci 10:57-63.

Szczypka MS, Mandel RJ, Donahue BA, Snyder RO, Leff SE, Palmiter RD (1999) Viral gene delivery selectively restores feeding and prevents lethality of dopamine-deficient mice. Neuron 22:167-178.

Trupp M, Belluardo N, Funakoshi H, Ibanez CF (1997) Complmentary and overlapping expression of glial cell line-derived neurotrophic factor (GDNF), c-ret proto-oncogene, and GDNF receptor-a indicates multiple mechanisms of trophic actions in the adult rat CNS. J Neurosci 17:3554-3567.

Ungerstedt U, Arbuthnott G (1970) Quantitative recording of rotational behavior in rats after 6-hydroxydopamine lesions of the nigrostriatal dopamine system. Brain Res 24:485-493.

West MJ, Slomianka L, Gundersen HJG (1991) Unbiased stereological estimation of the total number of neurons of the rat hippocampus using the optical fractionator. Anat Rec 231:482-497.

Winkler C, Sauer H, Lee CS, Björklund A (1996) Short-term GDNF treatment provides long-term rescue of lesioned nigral dopaminergic neurons in a rat model of Parkinson's disease. J Neurosci 16:7206-7215. 